\title{
FORMATO AULA-TALLER EN ESTUDIANTES DE PRIMARIA: APRENDIZAJE Y ENSEÑANZA
}

\author{
Nancy Núñez Soler \\ Universidad Internacional Iberoamericana (UNINI) \\ nancy.n@adinet.com.uy http://orcid.org/0000-0002-4665-4355 \\ Mariela Lourdes González \\ marielalourdesgonzalez@yahoo.com.ar \\ Jimena Aguirre \\ aguirrejimena1978@gmail.com https://orcid.org/0000-0001-8681-247X
}

\begin{abstract}
Resumen. La imposibilidad de la escuela tradicional para dar respuestas a las demandas sociales y laborales exige llevar adelante modificaciones en el formato escolar. En esta investigación proponemos el formato Taller como innovación. El propósito de este artículo es dar a conocer el análisis que se realizó del nuevo formato, su influencia en la motivación y en la mejora de los logros de aprendizaje de los estudiantes de nivel primario en Paysandú, Uruguay, así como los cambios que experimentan las prácticas docentes durante su puesta en acción. Se puso en práctica una metodología mixta bajo un enfoque secuencial comparativo sobre una población de 172 alumnos de $4^{\circ}$ a $6^{\circ}$ grado, y 19 docentes distribuidos en dos escuelas. Se usó un diseño cuasi-experimental con un grupo control y otro experimental. Se aplicó a los estudiantes, Diagnóstico Integral de Estudio (DIE I) e Inventario de Estilos de Aprendizaje (ILS) y a los docentes: Cuestionario de Dilemas y Análisis de documentos. Los resultados obtenidos mostraron la necesidad de modificar formatos escolares tradicionales, la incidencia positiva de un nuevo formato en la motivación y la mejora de los logros educativos. Comprobamos que, propuestas colaborativas, participación activa del niño como sujeto de su aprendizaje, tiempos desestructurados ayudan a los alumnos a mejorar su actitud ante el estudio, están motivados, comienzan el proceso de autorregulación en sus tareas y optimizan su rendimiento. La nueva modalidad impacta también en los docentes, ya que tienen necesidad de organizar su propuesta didáctica para atender las necesidades reales de sus alumnos.
\end{abstract}

Palabras clave: escuela primaria, método pedagógico-taller, motivación, aprendizaje activo.

\section{CLASSROOM-WORKSHOP FORMAT IN ELEMENTARY STUDENTS: LEARNING AND TEACHING}

\begin{abstract}
The impossibility of the traditional school to respond to social and labor demands requires carrying out modifications in the school format. In this investigation we propose the Workshop format as innovation. The purpose of this article is to publicize the analysis that was carried out of the new format, its influence on motivation and on the improvement of the learning achievements of primary level students in Paysandú, Uruguay, as well as the changes that the teaching practices during its implementation. A mixed methodology was implemented under a comparative sequential approach on a population of 172 students in grades 4-6, and 19 teachers distributed in two schools. A quasi-experimental design was used with a control group and an experimental group. It was applied to students, Comprehensive Study Diagnosis (DIE I) and Inventory of Learning Styles (ILS) and to teachers: Dilemma Questionnaire and Document Analysis. The results obtained showed the need to modify traditional school formats, the positive impact of a new format on motivation and the improvement of educational achievements. We verify that, collaborative proposals, active participation of the child as the subject of their learning, unstructured times help students improve their attitude towards the study, are motivated, begin the process of self-regulation in their tasks and optimize their performance. The new modality also impacts teachers, as they need to organize their teaching proposal to meet the real needs of their students.
\end{abstract}

Keywords: primary school, pedagogical method-workshop, motivation, active learning. 


\section{Introducción}

Las políticas educativas no pueden concebirse y ponerse en práctica al margen de los debates internacionales. El discurso educativo internacional actual versa sobre el mejoramiento de la calidad de los aprendizajes. Sin embargo, cuando se habla de calidad educativa se abre un escenario de interpretaciones diferentes. El Foro Mundial de Educación realizado en Inchon, República de Corea, en 2015 a instancias de UNESCO, deja instalada una nueva visión de educación hacia el año 2030. Los participantes se comprometieron a garantizar una educación inclusiva, equitativa y de calidad y promover oportunidades de aprendizaje durante toda la vida para todos.

El Sistema Educativo Uruguayo, con la finalidad de disminuir las desigualdades y brechas entre las escuelas, ha resuelto dar más apoyo a quienes están más desprovistos de recursos de todo tipo (materiales, cognitivos, sociales) para aprender. Mediante una estrategia focalizada, se ha dotado de mayores recursos e insumos a los centros educativos que atienden a los niños económicamente más pobres compensando en parte la desventaja inicial con la que enfrentan el aprendizaje los sectores marginados. "Las políticas compensatorias, logran muchas veces, mejorar las condiciones del hábitat escolar, pero no siempre se traducen en mayores o mejores aprendizajes" (Martinis y Stevenazzi, 2014, p.153)

Los resultados insatisfactorios sobre la calidad actual de la educación, consecuencias de haber desestimado la motivación de los estudiantes, el desinterés provocado por la enseñanza tradicional y el arraigo de ciertas prácticas rutinarias, ha tenido una repercusión social. Las familias ya no perciben a la escuela como una herramienta de movilidad social y cultural para sus hijos. El rezago, la repetición, el fracaso escolar surgen como consecuencia de los bajos resultados.

El formato escolar tradicional se ve interpelado por las necesidades educativas del mundo actual. Hablar de formato tradicional es hacer referencia a una modalidad graduada de escuela, que evidencia ciertas marcas, tales como: la organización de los niños por edad para cada grado, diferenciación de asignaturas, graduación de tiempos y espacios, grupos a cargo de un docente, el aula como unidad espacial, el año escolar como unidad temporal, entre otros. Para promover cambios beneficiosos en la educación tendrá que haber un "desplazamiento desde un modelo estructural estático, entendido como inacción, a otro dinámico, entendido como efecto o estructura" (Barber y Murshed, 2008, p.41). Las prácticas tradicionales están ordenadas en torno a un pasado revestido de autoridad que ya no da respuestas a las necesidades educativas. Pasar de un modelo a otro implica romper con el perfil de docente que aún sobrevive en nuestras instituciones, transformar el prototipo de docente individualista en un docente colaborativo; romper con la postura hegemónica para transitar hacia una postura heterónoma, en la cual la criticidad, la reflexión y el pensamiento divergente sean la cuna de la creatividad y la productividad de conocimiento, construyendo una senda hacia la mejora de la calidad educativa. El taller constituye un lugar de aprendizaje compartido, en el que todos sus participantes construyen socialmente conocimientos y valores, desarrollan habilidades y actitudes, a partir de sus propias experiencias.

El docente tallerista ve interpelado constantemente su rol en la relación pedagógica, su formación inicial, su formación permanente, su integración al equipo institucional y al desarrollo de su carrera profesional.

El Aula-Taller se presenta como una metodología que despierta en el alumno el interés indagatorio y la curiosidad. Que tiene la particularidad que cambia el foco de atención del maestro al alumno ya que es el propio niño quien va diseñando su proceso 
de aprendizaje siguiendo sus motivaciones. Se trata de una forma de práctica educativa de carácter paido-céntrica ya que el acento se pone en el alumno.

Esta investigación contribuye al enriquecimiento de los debates públicos, a la reflexión de los educadores y al análisis de los expertos a través de estudios sistemáticos respaldados en evidencia; el estudio pretende ser un insumo útil para la identificación de problemas en las aulas y la formulación de nuevas políticas educativas. La baja calidad es visualizada según los resultados de pruebas estandarizadas de aprendizajes y de indicadores como causa de la repetición escolar. Ineludiblemente, se asocia calidad educativa a los buenos resultados de aprendizaje. Éstos deben valorarse desde dos perspectivas, por un lado, el rendimiento escolar y, por otro, la satisfacción de la comunidad educativa.

El formato escolar uruguayo que podríamos llamar "tradicional" consiste en organizar a los alumnos por edad cronológica y asignarlos a grados escolares que se extienden desde Inicial ( 3 años) hasta sexto año de Primaria en un rango etario entre los 3 y los 12 años. La escuela, desde su creación, ha tenido el mandato de formar a los futuros ciudadanos transmitiéndoles los valores culturales que hacen a la identidad nacional. En las últimas décadas, la necesidad de ampliar la cobertura llevó a priorizar más la cantidad de niños en las escuelas en desmedro de la calidad del servicio. Un aumento en los niveles de cobertura genera tensión sobre el estándar de calidad en cualquier país.

El problema en materia de cobertura, a partir de una alta deserción en el ciclo medio y, consecuentemente, una baja tasa de culminación del ciclo, es insoslayable. En términos comparados, Uruguay es uno de los tres países en América Latina, después de Brasil y Bolivia, con menor tasa de culminación del ciclo superior de la educación media y uno de los tres que menos ha avanzado al respecto en la última década, según informe emitido por la Comisión Económica para América Latina y el Caribe (CEPAL, 2017). En sociedades con acceso segmentado, la calidad tenderá a segmentarse consecuentemente, reforzando la desigualdad de oportunidades futuras y erosionando el apoyo de las clases medias al bien público que supone tener un sistema educativo inclusivo y de calidad (Bogliaccini, 2018).

\section{Antecedentes}

Echando una mirada sobre Latinoamérica encontramos un estudio en Colombia realizado por el sociólogo Aponte Penso (2015). Se trató de una investigación en el ámbito de la Educación Superior con el fin de conocer el valor del Taller como estrategia metodológica para estimular la investigación. Los hallazgos lo validan como un instrumento donde interactúan estudiantes y docente, teoría y práctica, conocimiento y acción. En virtud a los resultados alcanzados, el taller pedagógico es visto por los docentes como una metodología adecuada para ser aplicada en el aula durante el proceso de enseñanza como estrategia que propicia espacios con ambientes adecuados al medio educativo y para estimular la investigación. Además indicaron que su utilización promueve entre los estudiantes lazos de amistad y afectividad, aspectos relevantes, a la hora de desarrollar trabajo en equipo, siendo una de sus características principales. De igual manera manifestaron que, a través del taller, se logra que los alumnos construyan el conocimiento de manera autónoma e independiente, partiendo del nivel teórico en interacción con sus pares, para ser transformados en nuevos conceptos, que son fundamentales en el desarrollo de sus competencias cognitivas. 
Siguiendo el rastreo bibliográfico se accedió a una reciente investigación realizada por Vargas (2018) en Perú, relacionada con el Taller de coaching como instrumento para mostrar la apatía escolar como consecuencia de la falta de una dinámica adecuada y aplicada a niños de quinto grado de secundaria de un colegio privado. La investigadora encontró un factor repetido en los métodos de enseñanza de los países con mejores niveles educativos y se trata de la participación del alumno en el desenvolvimiento de la clase, así como de las didácticas empleadas.

Se puede considerar como el punto de partida de este estudio, una investigación realizada por Martinis y Stevenazzi (2014) ya que ambas se efectúan en un mismo territorio y sobre el mismo universo poblacional. Los autores presentaron un proyecto de investigación que tiene que ver con abordar el estado de desarrollo del formato escolar moderno en Uruguay, así como analizar experiencias en curso en la educación primaria del país que pudieran ser de interés en cuanto a la generación de alteraciones sobre las formas de concebir y desplegar dicho formato. Trabajaron sobre dos escuelas públicas: una del ámbito rural y otra integrante del Programa de Maestros Comunitarios y, entre otros aspectos, plantean la necesidad de pluralizar los espacios educativos, como forma de habilitar la experimentación de diferentes formas de aprender y enseñar. (Martinis y Stevenazzi, 2014, p.19)

En esta línea, nuestro estudio visibiliza la efectividad de algunos formatos pedagógicos, especialmente el Taller, en los procesos de aprendizaje de los niños. Tiene además un interés científico, dado que pretende analizar si esos espacios alternativos fortalecen los procesos de aprendizaje específicamente en la faz motivacional y en lo que tiene que ver con la actitud y el auto-concepto. Pretende describir el formato Taller como herramienta para mejorar la calidad de la educación que se ofrece en el departamento de Paysandú; volver a entusiasmar a los niños que encontrarán dentro de la institución aquello que satisfaga sus intereses, recuperar matrícula perdida ya sea por asistencia intermitente o abandono, y disminuir las posibilidades de fracasar dentro del sistema. Al instalar el foco en el alumno ofrece una alternativa interesante para evitar la deserción, el rezago y el fracaso escolar.

\section{Acercamientos teóricos}

Adherimos a una nueva propuesta de aprendizaje que prepare a los alumnos para ser creativos y enfrentar los desafíos del Siglo XXI. Nos situamos en una visión de ciudadano como sujeto múltiple, cuya condición social e histórica encarna contradicciones de clase, de género y sexuales, étnico -raciales, diferencias territoriales, desigualdades sociales.

Fullan y Langworthy (2014) desarrollan una nueva pedagogía emergente, el aprendizaje en profundidad, como respuesta a la crisis del aburrimiento y la frustración tanto de alumnos como de docentes. Ayudar a los estudiantes a aprender acerca de sí mismos como alumnos y evaluar y reflexionar continuamente sobre sus propios progresos, es esencial para este proceso. El aprendizaje en profundidad se define como "la creación y utilización de nuevos conocimientos en el mundo" (Fullan y Langworthy, 2014, p.32). Los resultados del aprendizaje se miden en términos de 1) las capacidades de los alumnos para desarrollar nuevos conocimientos y para dirigir su propio aprendizaje de forma eficaz, 2) las actitudes proactivas y sus capacidades para perseverar a través de los desafíos, y 3) el desarrollo de personas cívicamente responsables que sean alumnos de por vida. 
A pesar de que a nivel mundial se opina que los estudiantes precisan destrezas como el pensamiento crítico y la capacidad de comunicarse con eficacia, innovar y resolver problemas mediante la negociación y la cooperación, la pedagogía no se ha adaptado para enfrentarse a estos nuevos retos. El modelo de clase magistral o de transmisión sigue siendo el enfoque instructivo predominante en gran parte del mundo (Saavedra y Opfer, 2012). Este planteamiento suele generar indiferencia, apatía y, en la mayoría de las personas, aburrimiento. Los autores mencionados sostienen que los educandos no desarrollan las competencias y habilidades necesarias a menos que se las enseñen de manera explícita.

Las prácticas docentes que promueven la creación de comunidades de aprendizaje positivo son las que ayudan eficazmente a conseguir un aprendizaje más profundo mediante la adquisición de conocimientos de contenido y el desarrollo de competencias intrapersonales e interpersonales.

Las investigaciones sobre la manera en que las personas aprenden proporcionan una valiosa información sobre la forma en que las distintas pedagogías ayudan a los estudiantes a dominar las habilidades y competencias del siglo XXI, y sobre cómo atraerlos y prepararlos para un futuro complejo y en perpetua mutación. El aburrimiento puede destacarse como la principal característica que mencionan tanto los estudiantes de trayectoria de rezago como de trayectoria esperada cuando se les pide que describan la educación. Esta situación es consistente con la evidencia reflejada en las respuestas que dan los jóvenes de entre 15 y 17 años que abandonaron la educación media, en el marco de la Encuesta Nacional de Adolescencia y Juventud: casi el $80 \%$ señala la falta de interés como una de las razones que los llevaron a abandonar. La Encuesta fue impulsada por el Instituto Nacional de la Juventud del Ministerio de Desarrollo Social, el Instituto Nacional de Evaluación Educativa, el Instituto Nacional de Estadística y la Facultad de Ciencias Sociales de Universidad de la República a través del Departamento de Sociología, en el año 2013.

Para contrarrestar el fracaso y el rezago escolar no se puede ignorar el valor del deseo de aprender por parte de los alumnos. Éste elimina la apatía, el aburrimiento, relaciones interpersonales insatisfactorias, baja autoestima, actitudes negativas hacia la escuela y hacia los pares, escaso rendimiento escolar.

\section{Método}

El estudio se llevó a cabo en dos escuelas A.PR.EN.D.E.R. (Atención Prioritaria en Entornos con Dificultades Estructurales Específicas) correspondientes al quintil 1, de las cuales se tomó una como grupo control y otra como grupo experimental. Nos circunscribimos al segundo ciclo de $4^{\circ}, 5^{\circ}$ y $6^{\circ}$ año. Las escuelas quintil 1 tienen como característica: un porcentaje del $20 \%$ o más de repetición en primer año, más del $50 \%$ de niños que concurren al comedor escolar, están enclavadas en contextos socio-culturales vulnerables, familias con baja escolaridad y pocas expectativas hacia los centros educativos. Se trata de escuelas que hasta el año 2014 fueron perdiendo paulatinamente matrícula por la baja oferta educativa y obtuvieron altos porcentajes de repetición pese a contar con recursos humanos calificados.

En marzo del año 2016, en una de las escuelas seleccionadas se implementó una modalidad innovadora para el departamento: el Tiempo Extendido. En el Reglamento de Tiempo Extendido publicado por el Consejo de Educación Inicial y Primaria (2013) se especifican las características de las escuelas que se transformen a esta modalidad. 
Consisten en jornadas de 7 horas en las que se identifican 2 horas de talleres, 1 hora para almuerzo que incluye espacios de recreación, y 4 horas de clase con un maestro de aula. Con esta modalidad, comienzan a circular en la escuela otros saberes, otros tiempos, otras organizaciones espaciales que suponen una innovación al formato tradicional. La inclusión de Profesores Talleristas con metodologías, tiempos pedagógicos y propósitos diferentes a los docentes de aula, imprime una dinámica diferente a las organizaciones.

\section{Diseño metodológico}

Para responder a las preguntas de investigación planteadas se desarrolla una metodología mixta que integra lo cuantitativo y lo cualitativo en un solo estudio. Es un diseño de investigación flexible, se siguen solo lineamientos orientadores. Se ha optado por un diseño cuasi-experimental con grupo control y sin asignación aleatoria. En este diseño los sujetos no se asignan al azar a los grupos ni se emparejan, sino que dichos grupos ya están conformados antes del experimento y se integran independientemente del mismo. Facilitan el desarrollo del estudio en el ambiente natural del aula y permiten inferir relaciones causales entre las variables independiente y dependiente. Para contrarrestar una de las debilidades del método cuasi experimental se decidió trabajar con dos grupos: uno experimental en el que se aplica una metodología pedagógica nueva para la institución y otro de control con metodologías pedagógicas tradicionales.

En ambos grupos se aplicó un pre y un pos test en los que se observó si el formato Taller fue capaz de mejorar el rendimiento general de los alumnos en el aspecto académico a lo largo del ciclo escolar (marzo a diciembre) y si se vieron mayores indicios de motivación en las tareas.

\section{Instrumentos}

Los instrumentos se emplearon en función de los estamentos de la muestra. A los alumnos, como pre y post test, se administraron dos instrumentos estandarizados en aplicación colectiva: 1) Test de Diagnóstico integral de estudio (Pérez, Rodríguez, Cabezas y Polo, 2002); y 2) Inventario de Estilos de Aprendizaje, versión española (Vermunt y Verloop, 2000), posterior adaptación al nivel primario latinoamericano (Villar, 2013) y re adaptación a la realidad uruguaya (2017).

A los docentes se les aplicó de modo colectivo un Cuestionario de dilemas sobre la enseñanza y el aprendizaje de Pozo, Scheuer, Pérez, Mateos, Martín y De la Cruz (2006) validado por Vilanova, Mateos-Sanz y García (2011) y se hizo un análisis documental.

Para la información recogida se empleó el programa IBM® SPSS® versión 25.0 mediante el cual se realizó el estudio proporcional y comparativo de las respuestas categorizadas de cada ítem en cada test.

El software utilizado a lo largo del proceso de análisis de la información corresponde a los programas:

- Microsoft ${ }^{\circledR}$ Excel® versión 2016: manejo de la data original, transposición de matrices, ordenación de tablas, cálculo de estratos, conversiones de codificaciones y conversión de archivos a formato de Base. 
- $\quad$ IBM® SPSS $®$ versión 25.0: utilizado para el procesamiento de bases de datos e información estadística cuantitativa, diseño y desarrollo de tablas e informes descriptivos y multivariados. También se utilizó la interfaz de generación y análisis de gráficos estadísticos.

- Formularios de Google®: utilizados para la elaboración de cuestionarios sobre una plataforma web en un lenguaje HTML. Estos se convierten en una valiosa interfaz de carga de datos relevados para la generación de una compleja e integral base de datos.

- Google ${ }^{\circledR}$ Drive: Utilizado como soporte de almacenamiento virtual de información.

La escuela que será objeto de investigación (EE) fusiona las Escuelas $\mathrm{N}^{\circ} 190$ de Práctica docente y la $\mathrm{N}^{\circ} 138$ A.PR.EN.D.E.R la que se mencionará en esta investigación y a efectos de conservar la confidencialidad, como Escuela $\mathrm{N}^{\circ} 201$.

El alumnado ha decrecido en los últimos cinco años dado que hay en la zona un colegio privado que absorbe matrícula de familias con mejores ingresos económicos. Ofrece servicio de comedor escolar y de merienda para la totalidad del alumnado de la escuela. Funciona entre las 10 y las 17 horas. Según datos del Monitor educativo (CEIP, 2015) la escuela contaba con 193 alumnos siendo que escuelas de igual categoría tienen un promedio de 369 y de igual contexto 296 . Registra una asistencia insuficiente de $1^{\circ}$ a $6^{\circ}$ año de casi el $20 \%$ siendo que escuelas de igual categoría alcanzan solo el 5,4\%. En este centro se forman estudiantes magisteriales de tercer año de formación básica.

La escuela de control (EC) es también A.PR.EN.D.E.R. y contiene la práctica de $4^{\circ}$ año de Formación Docente, esto es los estudiantes que cursan su último año de práctica en territorio previo a graduarse. Se mencionará como Escuela $\mathrm{N}^{\circ} 178$. Funciona en doble turno. Brinda almuerzo a la totalidad de los niños. Son 13 los niños repetidores (6\%). En el año 2017 hubo un caso de deserción en sexto año, de 217 niños. En el presente año no hay caso de ausentismo, pero sí de asistencia intermitente (47), son niños que al momento tienen menos del $80 \%$ de asistencia a clase.

Ambas escuelas son públicas. En Uruguay las escuelas públicas son financiadas por el Estado. Nuestra propuesta de investigación se acota a la escuela pública, por dos razones fundamentales. En primer lugar, por el caudal de alumnos que atiende; casi el 90\% de los alumnos matriculados en Primaria en todo el país concurren a escuelas públicas según el Anuario Estadístico del Ministerio de Educación y Cultura (2016). En segundo lugar, porque entendemos que en ella se ven acentuadas las diferencias individuales en lo que hace a los contextos sociales, económicos y culturales.

\section{Resultados}

En un análisis descriptivo, realizamos el análisis de media, desviación estándar, mediana y puntajes mínimos y máximos para cada factor de análisis en cada una de las instancias del relevamiento. Para dicha operación se convirtieron todos los valores en escala 10 para una mejor comprensión y comparación de los resultados. 
Tabla 1

Valores descriptivos de los dos factores que componen el constructo Diagnóstico Integral de Estudio

\begin{tabular}{|c|c|c|c|c|c|c|c|c|}
\hline \multirow[b]{2}{*}{ Estadísticos descriptivos } & \multicolumn{4}{|c|}{ Primera Instancia } & \multicolumn{4}{|c|}{ Segunda Instancia } \\
\hline & $\begin{array}{l}\text { Ptje } \\
\text { Mín }\end{array}$ & $\begin{array}{l}\text { Ptje. } \\
\text { Máx } \\
\text {. }\end{array}$ & $\begin{array}{l}\text { Medi } \\
\text { a }\end{array}$ & D.E.* & $\begin{array}{l}\text { Ptje } \\
\text { Mín }\end{array}$ & $\begin{array}{l}\text { Ptje. } \\
\text { Máx } \\
\text {. }\end{array}$ & $\begin{array}{l}\text { Medi } \\
\text { a }\end{array}$ & $\begin{array}{l}\text { D.E. } \\
*\end{array}$ \\
\hline Actitud y Estrategias de Apoyo & 4 & 9,33 & $\begin{array}{l}6,625 \\
7\end{array}$ & $\begin{array}{l}1,2226 \\
5\end{array}$ & $\begin{array}{l}3,0 \\
0\end{array}$ & 9,67 & 7,219 & $\begin{array}{l}1,42 \\
9\end{array}$ \\
\hline $\begin{array}{l}\text { Autoconcepto y Estrategias } \\
\text { complementarias }\end{array}$ & 2 & 9 & $\begin{array}{l}5,967 \\
8\end{array}$ & $\begin{array}{l}1,4294 \\
1\end{array}$ & $\begin{array}{l}2,6 \\
7\end{array}$ & $\begin{array}{l}10,0 \\
0\end{array}$ & 7,970 & $\begin{array}{l}1,83 \\
2\end{array}$ \\
\hline Actitud y Estrategias complementarias & $\begin{array}{l}2,3 \\
3\end{array}$ & 10 & $\begin{array}{l}5,350 \\
9\end{array}$ & $\begin{array}{l}1,4306 \\
9\end{array}$ & $\begin{array}{l}1,6 \\
7\end{array}$ & 9,67 & 6,873 & $\begin{array}{l}1,85 \\
4\end{array}$ \\
\hline Autoconcepto y Estrategias de Apoyo & $\begin{array}{l}1,3 \\
3\end{array}$ & 9,67 & $\begin{array}{l}5,526 \\
3\end{array}$ & $\begin{array}{l}1,5277 \\
8\end{array}$ & $\begin{array}{l}1,3 \\
3\end{array}$ & 9,33 & 6,210 & $\begin{array}{l}1,74 \\
7\end{array}$ \\
\hline Estrategias de Apoyo & $\begin{array}{l}3,1 \\
7\end{array}$ & 9 & 6,076 & $\begin{array}{l}1,1212 \\
5\end{array}$ & $\begin{array}{l}3,3 \\
3\end{array}$ & 8,67 & 6,714 & $\begin{array}{l}1,31 \\
0\end{array}$ \\
\hline Estrategias complementarias & $\begin{array}{l}2,6 \\
7\end{array}$ & 9,5 & $\begin{array}{l}5,659 \\
4\end{array}$ & $\begin{array}{l}1,2272 \\
3\end{array}$ & $\begin{array}{l}3,5 \\
0\end{array}$ & 9,67 & 7,421 & $\begin{array}{l}1,70 \\
0\end{array}$ \\
\hline Actitud & $\begin{array}{l}3,1 \\
7\end{array}$ & 9,5 & $\begin{array}{l}5,988 \\
3\end{array}$ & $\begin{array}{l}1,1231 \\
3\end{array}$ & $\begin{array}{l}2,8 \\
3\end{array}$ & 9,00 & 7,046 & $\begin{array}{l}1,44 \\
9\end{array}$ \\
\hline Autoconcepto & $\begin{array}{l}2,8 \\
3\end{array}$ & 8,67 & $\begin{array}{l}5,747 \\
1\end{array}$ & $\begin{array}{l}1,2096 \\
5\end{array}$ & $\begin{array}{l}2,8 \\
3\end{array}$ & 9,33 & 7,090 & $\begin{array}{l}1,49 \\
4\end{array}$ \\
\hline Aptitud & $\begin{array}{l}3,2 \\
5 \\
\end{array}$ & 8,83 & $\begin{array}{l}5,867 \\
7\end{array}$ & $\begin{array}{l}1,0293 \\
6\end{array}$ & $\begin{array}{l}3,4 \\
2\end{array}$ & 9,00 & 7,068 & $\begin{array}{l}1,38 \\
0\end{array}$ \\
\hline
\end{tabular}

En la tabla 1 podemos observar que, de la totalidad de los casos analizados, las medias en la segunda instancia superan a las de la primera. También podemos analizar, en la figura 1, que los rangos en la primera instancia están más concentrados que en la segunda.

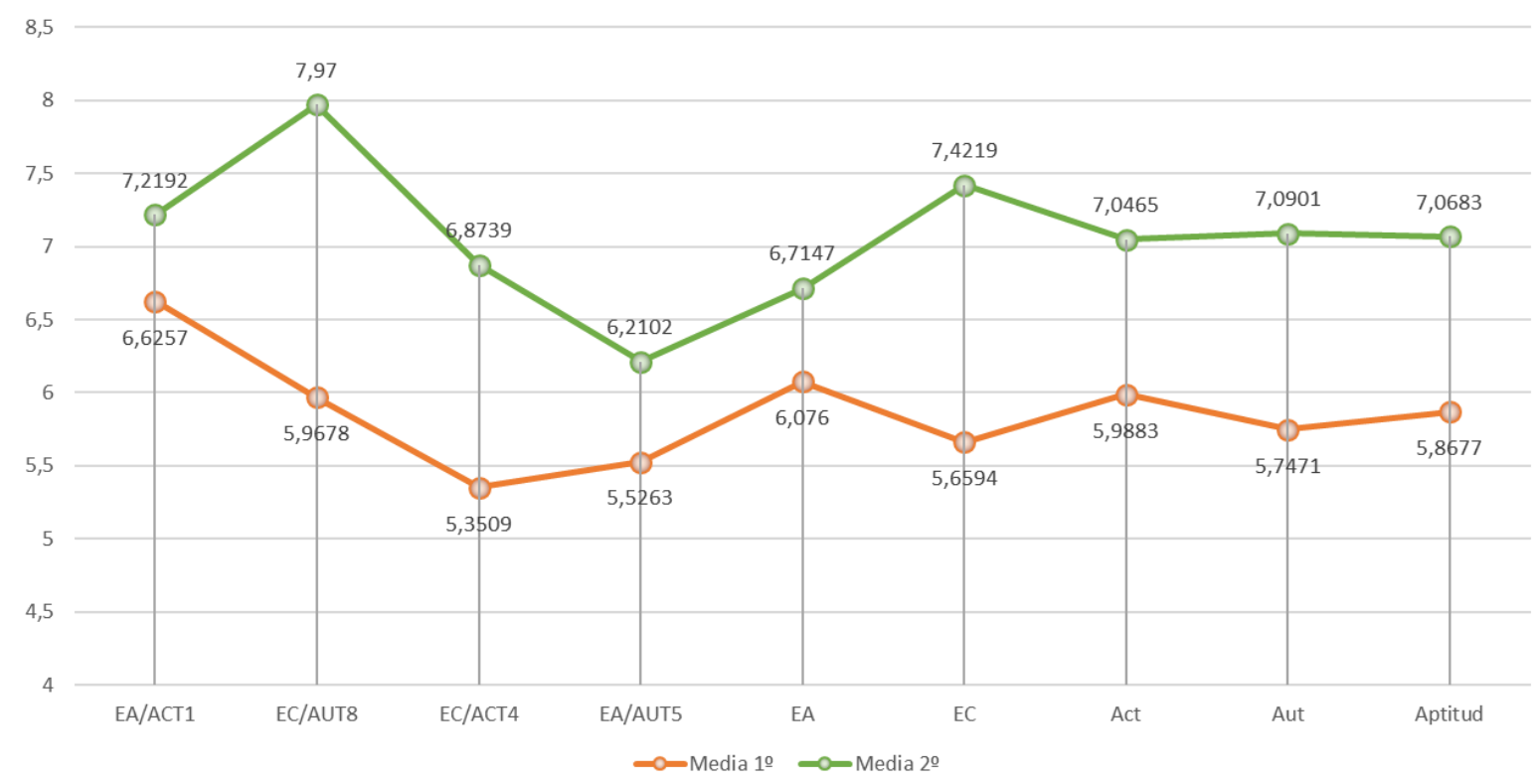

Figura 1. Distribución de Medias. Diagnóstico Integral de estudio 


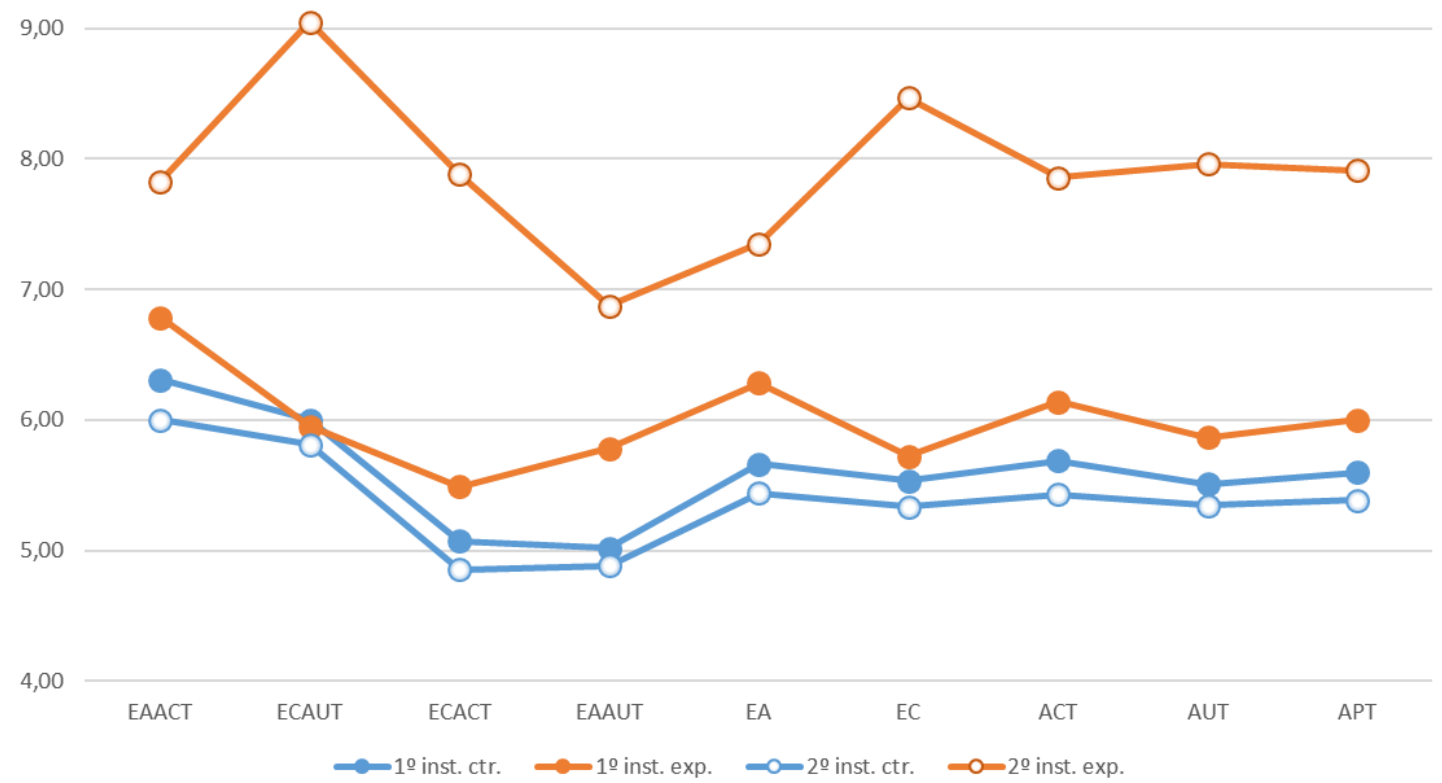

Figura 2. Análisis descriptivo por cada grupo (experimental y control) en pre y post test del Diagnóstico Integral de estudio

En las figuras 1 y 2 se puede apreciar cómo se distribuyeron las medias de ambos grupos en las dos instancias de relevamiento. El dato que sobresale es el de las medias del grupo experimental durante la segunda instancia de relevamiento (color naranja con puntos blancos) debido al incremento de valores respecto de la primera instancia de relevamiento (color naranja con puntos naranjas).

Otro dato interesante sobre el grupo control, es que en la segunda instancia de relevamiento (color azul con puntos blancos) decrecieron respecto de la primera instancia de relevamiento (color azul con puntos azules). Es decir, que los valores de las medias disminuyeron con el tiempo de manera casi proporcional para todos los factores de análisis en el grupo de control. Responde esta situación de alguna forma al agotamiento del modelo tradicional de enseñanza que, en lugar de ayudar a los alumnos a avanzar obstaculiza sus logros.

\section{1. ¿Me aburro en clase?}

Entendimos importante analizar específicamente el ítem 42 del Diagnóstico Integral de Estudio, que expresa: "me aburro en las clases", considerando que nuestro interés es saber si los estudiantes se motivan en los talleres o por el contrario se aburren y manifiestan desinterés y desgano. El aburrimiento es un estado emocional de letargo acompañado de una sensación de alargamiento del tiempo. 
Tabla 2

Comparación de respuestas afirmativas al Ítem 42 en las dos instancias de aplicación en las dos escuelas.

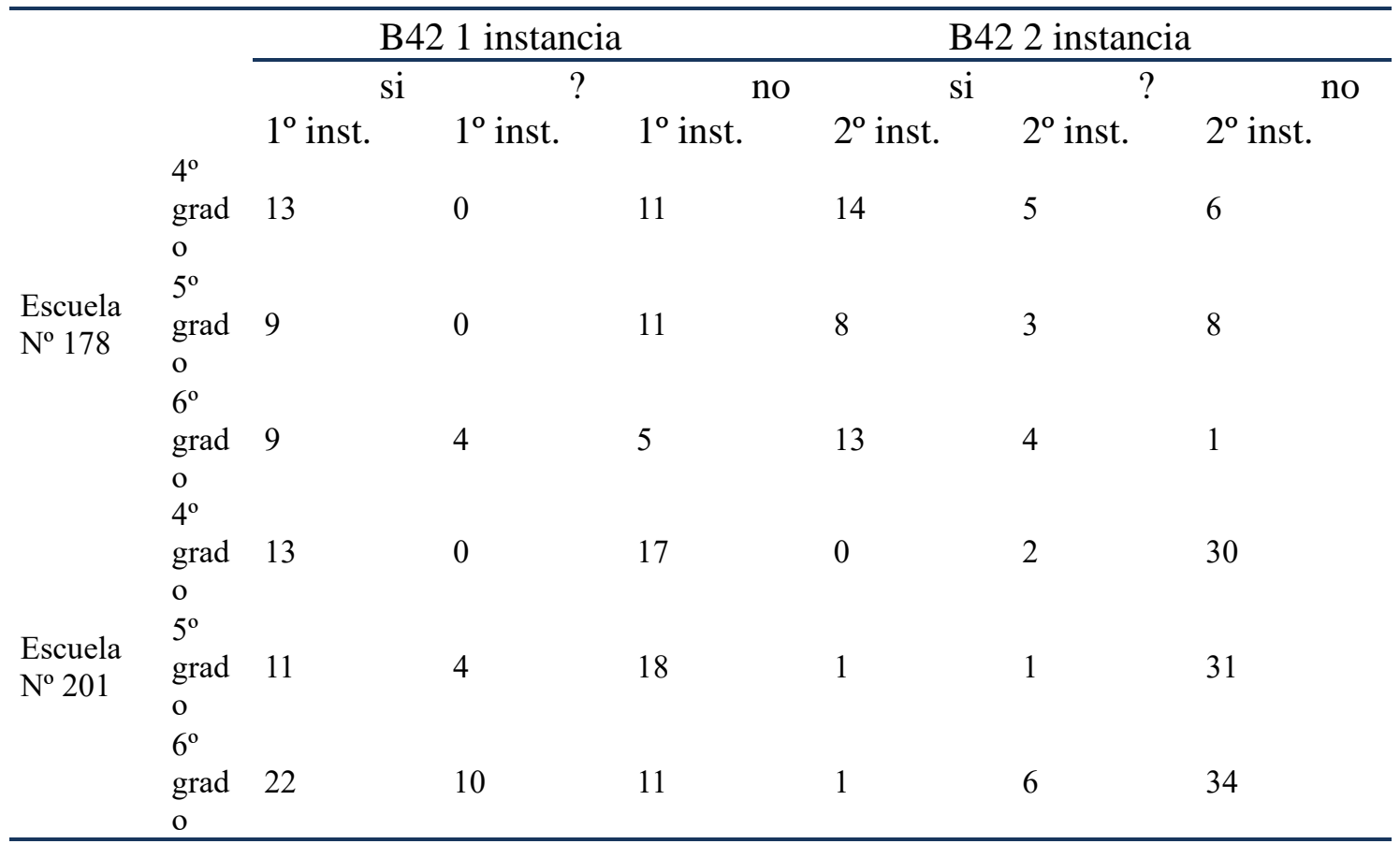

Observamos claramente que en la escuela en la que se ha instalado el Taller disminuyó el aburrimiento en clase. En $6^{\circ}$ año, concretamente, a comienzo de año indicaron aburrirse 22 niños y al finalizar el año solo uno mantuvo su respuesta. No ocurrió lo mismo en la EC, en $6^{\circ}$ año, 9 alumnos indicaron aburrirse en la primera instancia y fueron 13 los que respondieron afirmativamente en la segunda. El formato tradicional ya no entusiasma a los estudiantes, contrariamente los desmotiva.

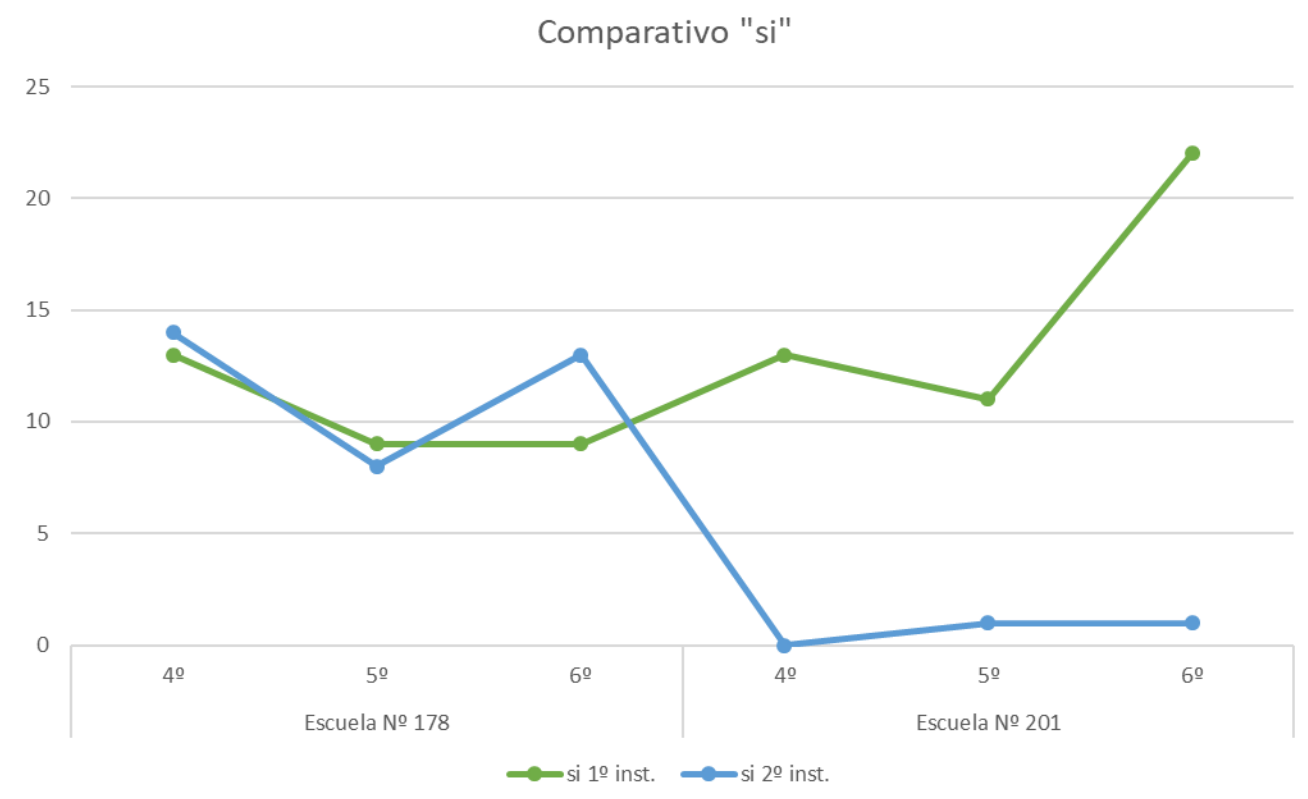

Figura 3. Comparativo del ítem 42 en la respuesta SI 
En la figura $\mathrm{N}^{\mathrm{o}} 3$ podemos observar qué ocurre con el aburrimiento según los grados y las escuelas de referencia. Tanto en la primera como en la segunda instancia los alumnos manifestaron aburrirse en clase casi en la misma proporción en la escuela control, en cambio, hay un margen pronunciado en la escuela experimental. Los estudiantes afirmaron aburrirse en clase en la primera instancia, pero descendieron drásticamente sus respuestas afirmativas en la segunda aplicación en la escuela experimental. Esto lo atribuimos al formato establecido, con mayor flexibilidad y adaptación a las necesidades de los alumnos que implica mayor involucramiento y menor posibilidad de aburrirse durante las actividades áulicas.

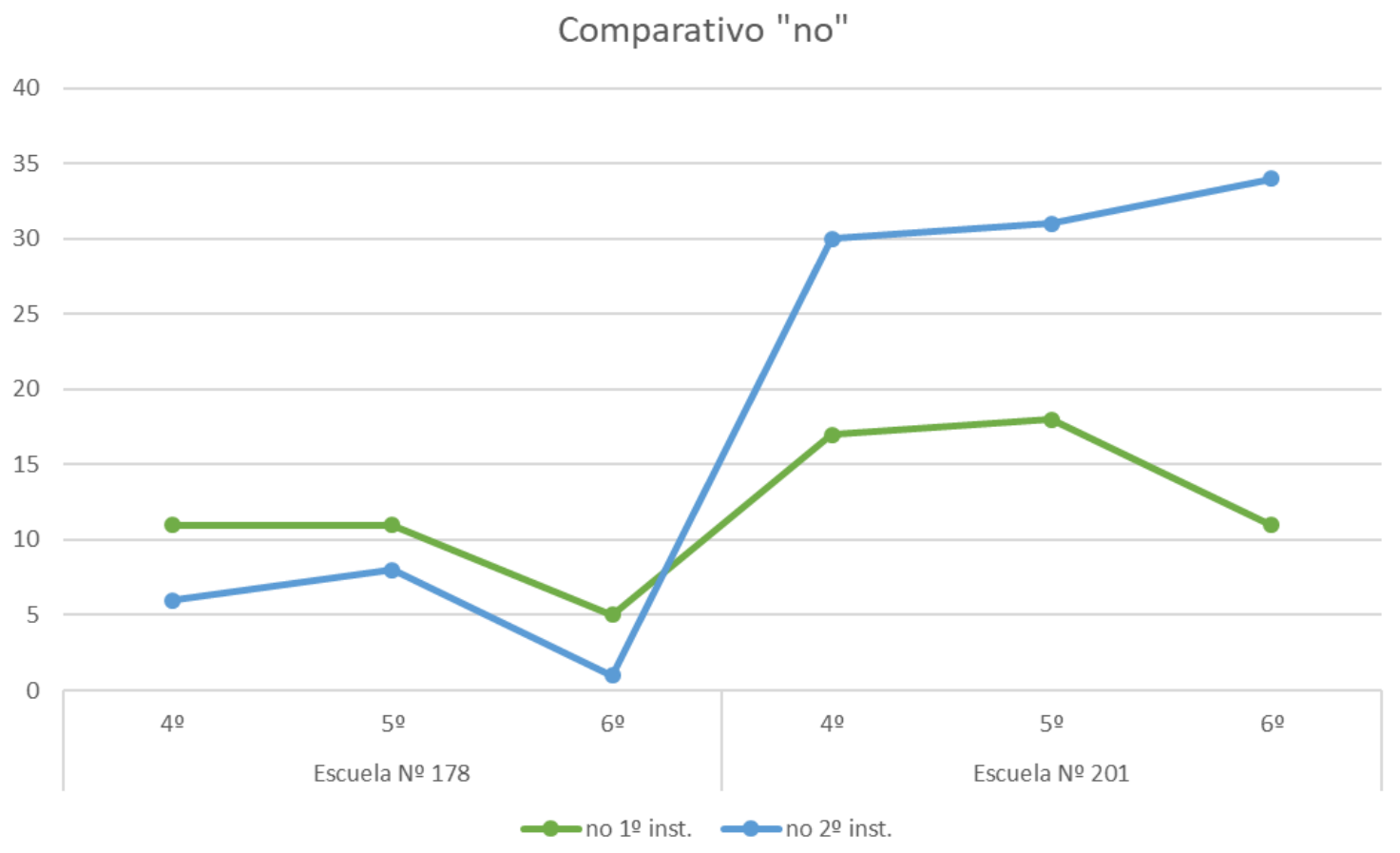

Figura 4. Comparativo del ítem 42 en la respuesta NO

En la figura $\mathrm{N}^{\mathrm{o}} 4$ podemos observar a la inversa. En la primera aplicación los alumnos de las dos escuelas respondieron mayoritariamente no aburrirse en clase. Sin embargo, a medida que avanzó el año escolar los estudiantes de la escuela experimental subieron exponencialmente sus respuestas negativas ante el aburrimiento. No pasó lo mismo en la escuela de control en donde las respuestas negativas descendieron.

A continuación, realizamos el análisis de media, desviación estándar, mediana y puntajes mínimos y máximos para cada factor de análisis en cada una de las instancias del relevamiento del Inventario de Estilos de Aprendizaje. Para dicha operación se convirtieron todos los valores en escala 10 para una mejor comprensión y comparación de los resultados. 
Tabla 3

Valores descriptivos de los factores que componen el constructo Inventario de Estilos de Aprendizaje para ambas instancias de relevamiento.

\begin{tabular}{l|l|l|l|l|l|l|l|l}
\cline { 2 - 8 } & \multicolumn{3}{c}{ Primera Instancia } & \multicolumn{1}{c}{ Segunda Instancia } \\
\hline Estadísticos descriptivos & Ptje. & Ptje. & Media & D.E.* & Ptje. & Ptje. & Media & D.E.* \\
& Mín. & Máx. & & & Mín. & Máx. & & \\
Autorregulación & 3,00 & 8,67 & 5,3714 & 0,09156 & 4,00 & 9,40 & 6,8889 & 1,79988 \\
Regulación Externa & 3,33 & 9,70 & 5,6594 & 0,10762 & 4,36 & 9,27 & 6,8134 & 1,43372 \\
Carencia de Regulación & 3,33 & 10,00 & 6,1293 & 0,10614 & 4,00 & 9,60 & 6,8351 & 1,43754 \\
\hline
\end{tabular}

D.E.: Desviación Estándar

En la tabla 3 podemos apreciar que, de la totalidad de los casos analizados en el pre test, las medias se ubican por encima de 5, sin embargo, en la segunda instancia las medias no bajan de 6,5. También podemos apreciar que los valores mínimos y máximos en la segunda instancia son más elevados que en la primera teniendo en cuenta que trabajamos con una escala de 1 a 10, lo que nos permitió homogenizar el análisis de factores.

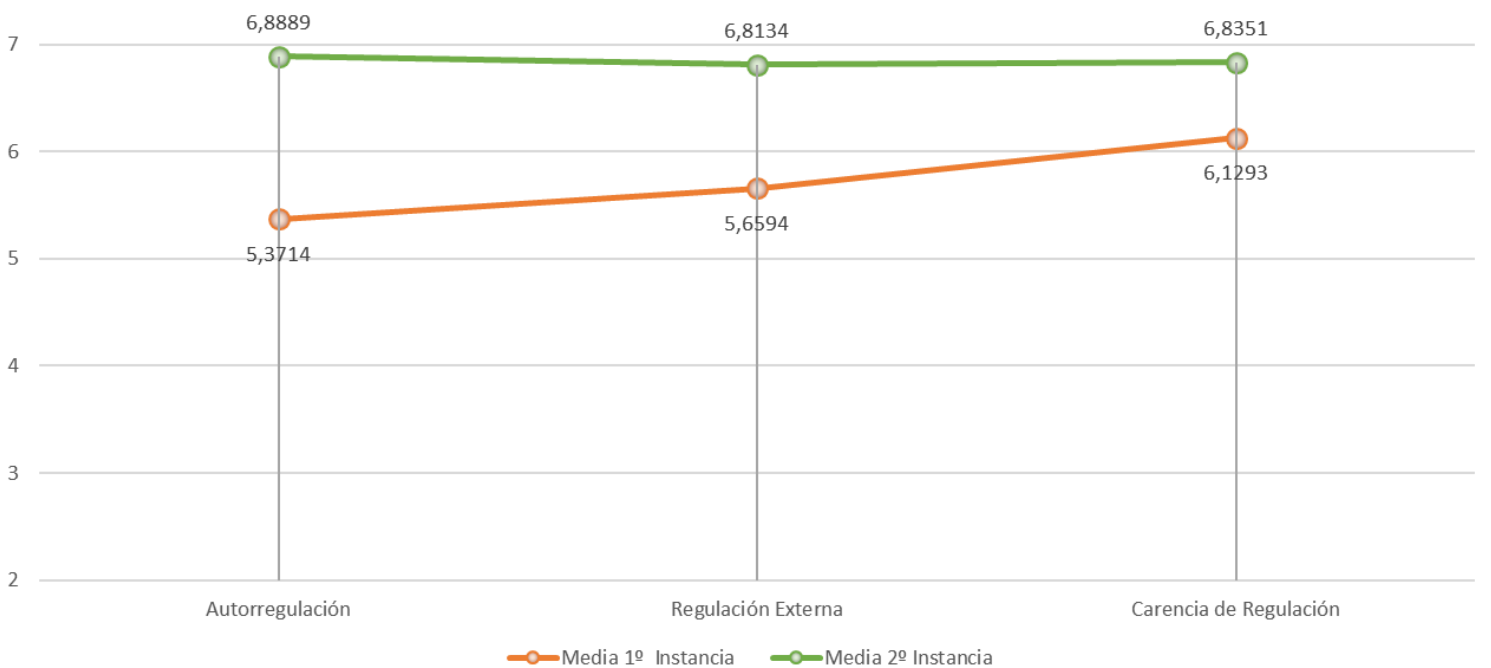

Figura 5. Distribución de Medias

En esta figura podemos observar la distribución de las medias de cada factor en cada una de las instancias de relevamiento. Evidentemente, las medias de la segunda instancia son superiores a las de la primera. 
Tabla 4

Valores descriptivos de los factores que componen el constructo Inventario de estilos de Aprendizaje para ambos grupos de ambas instancias

\begin{tabular}{|c|c|c|c|c|c|c|c|c|c|c|c|}
\hline \multirow{2}{*}{\multicolumn{2}{|c|}{ Estadísticos descriptivos }} & \multicolumn{5}{|c|}{ Grupo Control } & \multicolumn{5}{|c|}{ Grupo Experimental } \\
\hline & & Casos & Ptje. & Ptje. & Media & D.E.* & Casos & Ptje. & Ptje. & Media & D.E.* \\
\hline \multirow{3}{*}{$\begin{array}{l}1^{\circ} \\
\text { Instancia }\end{array}$} & Autorregulación & 75 & 1,00 & 2,40 & 1,575 & ,3255 & 97 & ,90 & 2,60 & 1,639 & ,3842 \\
\hline & Regulación Externa & 75 & 1,09 & 2,82 & 1,690 & ,3796 & 97 & 1,00 & 2,91 & 1,703 & ,4562 \\
\hline & Carencia de Regulación & 75 & 1,00 & 3,00 & 1,820 & 4505 & 97 & 1,00 & 2,80 & 1,853 & 3920 \\
\hline \multirow{3}{*}{$\begin{array}{l}2^{\circ} \\
\text { Instancia }\end{array}$} & Autorregulación & 74 & 4 & 6 & 4,889 & 0,383 & 97 & 7,4 & 9,4 & 8,414 & 0,437 \\
\hline & Regulación Externa & 74 & 4 & 6 & 4,975 & 0,383 & 97 & 7,45 & 10 & 8,384 & 0,442 \\
\hline & Carencia de Regulación & 74 & 4 & 7,2 & 5,502 & 0,823 & 97 & 5,6 & 9,6 & 7,851 & 0,855 \\
\hline
\end{tabular}

D.E.: Desviación Estándar

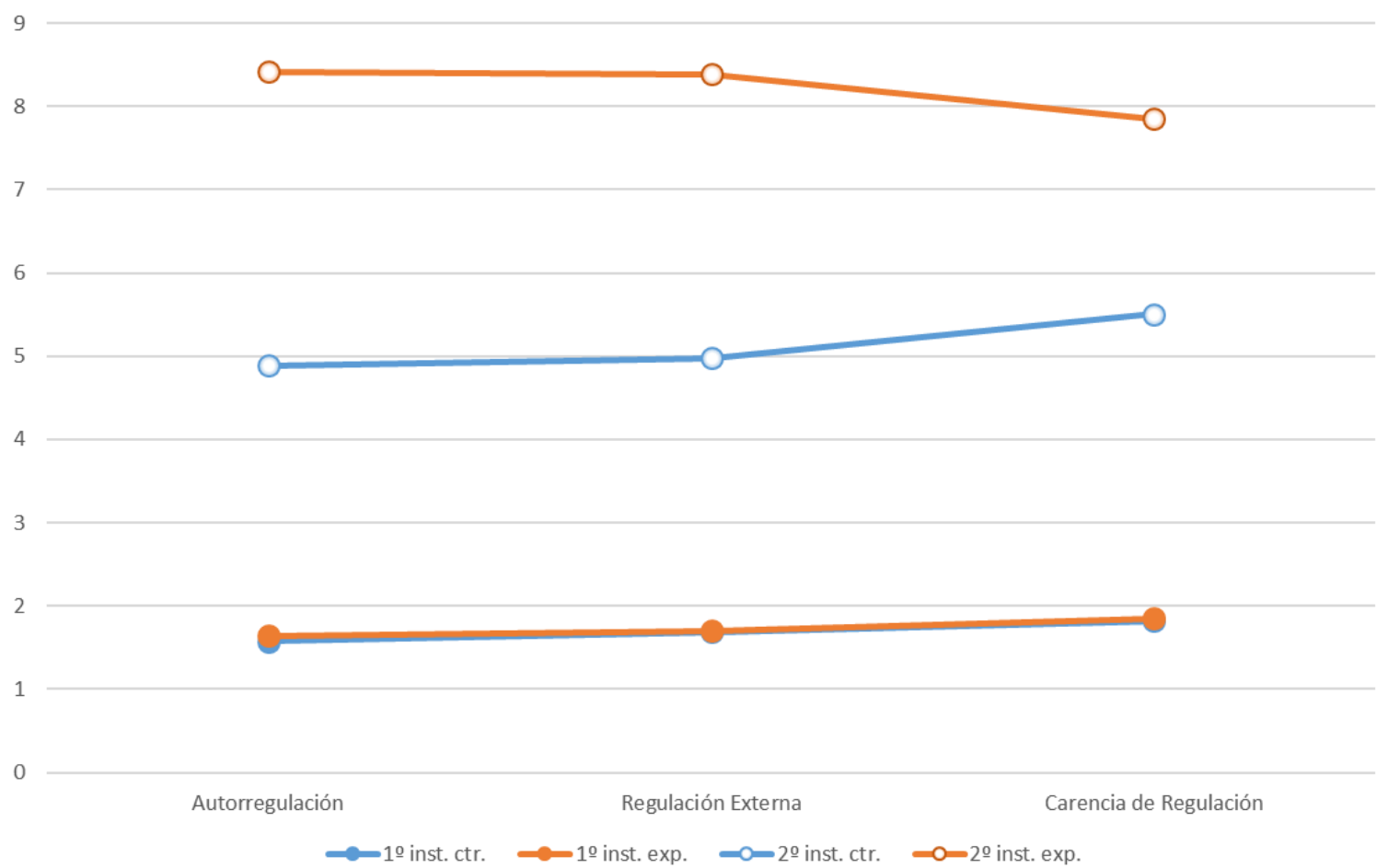

Figura 6. Análisis descriptivo por cada grupo (experimental y control) en ambas instancias

En la figura 6 se puede apreciar cómo se distribuyeron las medias de ambos grupos en las dos instancias de relevamiento. El dato que sobresale es el de las medias del grupo experimental durante la segunda instancia de relevamiento (color naranja con puntos blancos) debido al incremento de valores respecto de la primera instancia de relevamiento (color naranja con puntos naranjas)

Si bien, el grupo control (Líneas azules) también muestra un incremento significativo respecto a ambas instancias de relevamiento. El incremento en el grupo experimental de la segunda instancia (color naranja con puntos blancos) es muy superior al del grupo control en dicha instancia también (color azul con puntos blancos).

Cabe destacar que es elevado el nivel de homogeneidad entre ambos grupos en la primera instancia o punto de partida. 


\subsection{Resultados de rendimientos académicos}

Para medir el rendimiento académico se consideraron las calificaciones finales de cada alumno de los grupos seleccionados en la muestra.

Tabla 5

Calificaciones en quinto año de los niveles medio y alto

\begin{tabular}{llllllll} 
& & Control & \multicolumn{5}{c}{ Experimental } \\
\cline { 3 - 7 } Nivel Medio & & Cantidad & $\%$ & & Cantidad & $\%$ & \\
& B & 12 & 52 & 18 & 9 & 32 & 17 \\
& BMB & 3 & 13 & $78 \%$ & 6 & 21 & $55 \%$ \\
\multirow{5}{*}{ Nivel Alto } & MBB & 3 & 13 & & 2 & 7 & \\
& MB & 2 & 9 & 51 & 6 & 18 & 14 \\
\multirow{5}{*}{ Total } & MBS & 2 & 9 & 5 & 5 & 4 & $45 \%$ \\
\hline
\end{tabular}

En esta tabla se puede observar que hay un desplazamiento del nivel Bueno hacia el Alto en la Escuela Experimental dado que cerca de la mitad del grupo se encuentra en este último nivel. Hay una diferencia de 23 puntos porcentuales que pierde el nivel medio y lo gana el alto en quinto año. Se observa que la mayor diferencia está en las calificaciones Muy Bueno y Muy Bueno Sobresaliente, ambas pertenecientes al Nivel Alto.

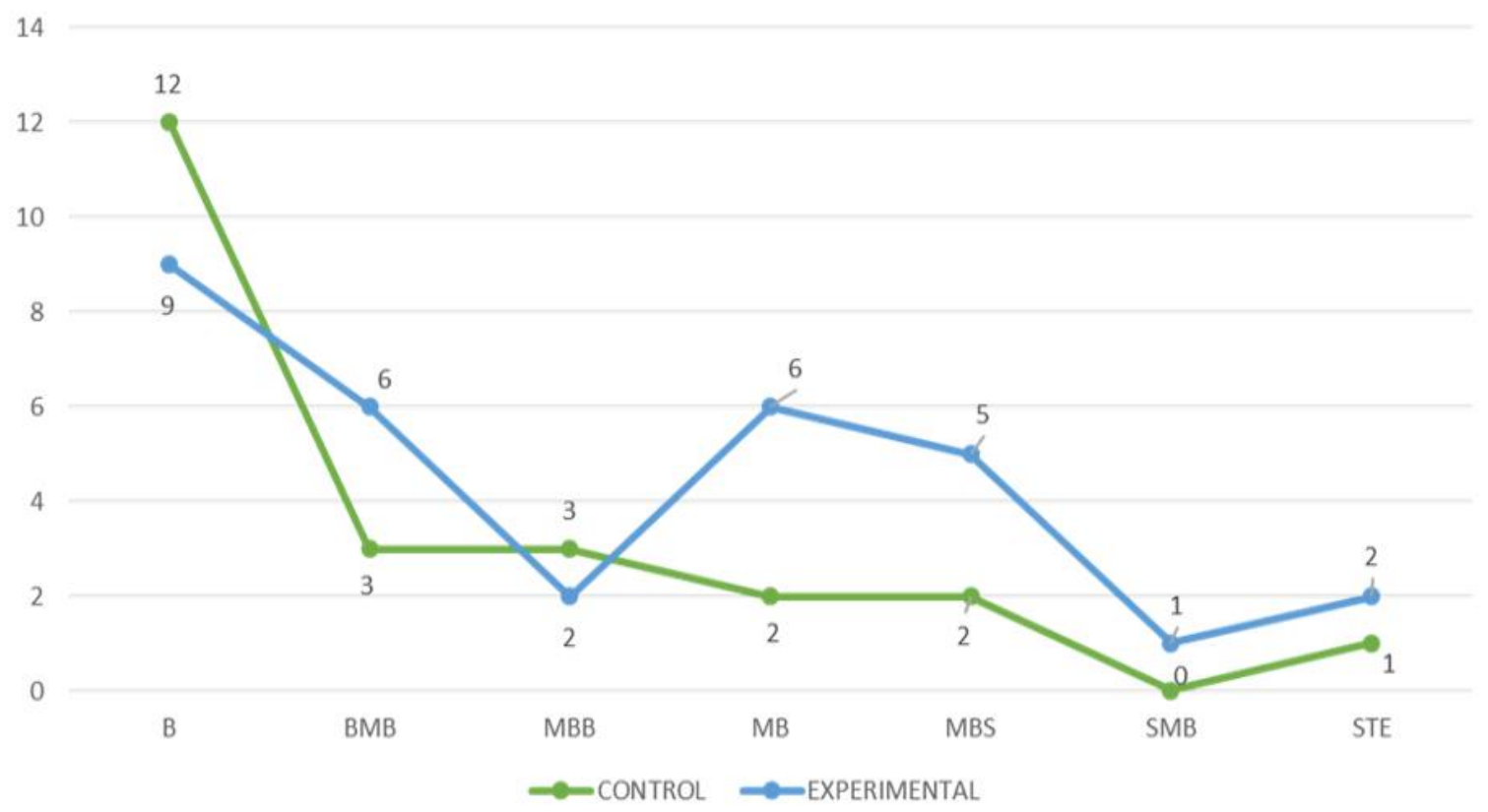

Tabla 6.

Calificaciones en sexto año de los niveles medio y alto

\begin{tabular}{|c|c|c|c|c|c|c|c|}
\hline & & \multicolumn{3}{|l|}{ Control } & \multicolumn{3}{|c|}{ Experimental } \\
\hline \multirow{4}{*}{ Nivel Medio } & & Cantidad & $\%$ & \multirow{4}{*}{$\begin{array}{l}17 \\
74 \%\end{array}$} & Cantidad & $\%$ & \multirow{4}{*}{$\begin{array}{l}26 \\
63 \%\end{array}$} \\
\hline & B & 5 & 22 & & 3 & 7 & \\
\hline & $\mathrm{BMB}$ & 10 & 43 & & 8 & 20 & \\
\hline & MBB & 2 & 9 & & 15 & 38 & \\
\hline Nivel Alto & MB & 3 & 13 & 6 & 3 & 7 & 15 \\
\hline
\end{tabular}




\begin{tabular}{llllllll}
\hline & MBS & 0 & 0 & $26 \%$ & 8 & 20 & $37 \%$ \\
& SMB & 1 & 4 & & 2 & 5 & \\
& STE & 2 & 9 & & 2 & 5 & \\
Total & & 23 & $100 \%$ & & 41 & 100 & \\
\hline
\end{tabular}

Observamos en la tabla que también en sexto año hay una mejora en las calificaciones, sin embargo, la diferencia es menos significativa que en quinto año. Hay 11 puntos porcentuales que pierde el Nivel Medio y lo gana al Alto.

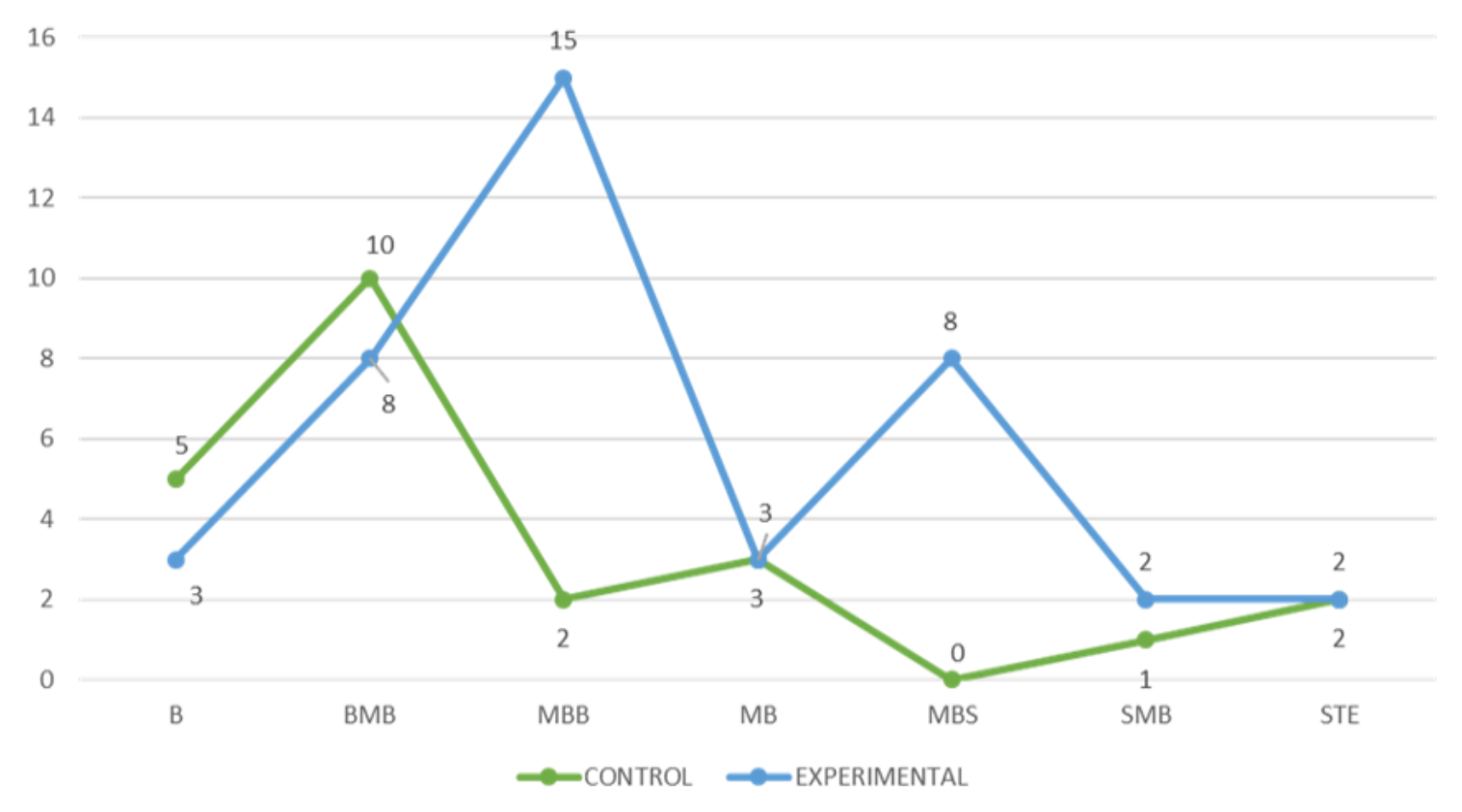

Figura 7. Gráfico comparativo de calificaciones en sexto año en Escuela Experimental y Escuela Control.

\subsection{Incidencia en la enseñanza}

Todo docente posee representaciones intuitivas que subyacen a sus prácticas y hasta muchas veces que difieren sustancialmente de sus concepciones manifiestas. Hay una diferencia conceptual entre percepciones y representaciones: los objetos de la percepción son visibles para muchos individuos; los contenidos de la representación, en cambio, son individuales y más profundamente arraigados en el hacer docente.

Para el análisis nos remitimos a los estudios de Pozo et al (2006) quienes han identificado tres teorías de dominio sobre el aprendizaje: directa, interpretativa y constructiva.

a. La teoría directa entiende el aprendizaje como un calco del modelo y algo meramente reproductivo. Hay un contenido disciplinar que se evalúa por resultados. Se aprende por repetición y por la incorporación de información adquirida ya sea a través de libros de textos o por clases frontales magistrales. Promueve el pensamiento convergente. Desconoce los procesos psicológicos; alcanza con crear buenas condiciones para conseguir resultados asumiendo así cierto determinismo. Hay una correspondencia directa entre el pensamiento y la acción.

b. En la teoría interpretativa, por su parte, si bien hay una reproducción del modelo acepta distintos caminos de resolución. Considera que el alumno debe aprender 
en forma activa tanto los contenidos como las competencias necesarias para procesar la información. Desde esta perspectiva el mejor modo de aprender consiste en observar intencionalmente a un experto. Actividades mentales como la memoria, la atención, las asociaciones, son consideradas importantes para el aprendizaje, lo mismo que el perfil pedagógico del profesor, pues actúa como modelo a seguir.

c. La teoría constructivista toma los conceptos de la interpretativa, pero le agrega la necesidad de autorregulación del aprendizaje por parte del propio alumno. Apoya las metodologías activas y la reflexión del aprendizaje. Supone un objeto que sufre necesariamente una transformación al ser aprehendido por el sujeto a través de su estructura cognitiva. La participación del sujeto en el aprendizaje y los procesos psicológicos implicados, constituyen el centro del problema y no existe un solo resultado óptimo, ya que el tipo de representaciones relacionadas con el objeto que la persona posee de antemano, el contexto en el que es aprehendido y los propósitos establecidos en función de dicho aprendizaje, son variables que intervienen en los resultados obtenidos.

Tabla 7

Valores descriptivos de los factores que componen el constructo Dilemas

\begin{tabular}{|c|c|c|c|c|c|c|c|c|c|c|}
\hline \multirow{2}{*}{$\begin{array}{l}\text { Factores } \\
\text { Teorías }\end{array}$} & \multicolumn{2}{|c|}{$\begin{array}{l}\text { qué es } \\
\text { aprender }\end{array}$} & \multicolumn{2}{|c|}{$\begin{array}{l}\text { qué } \\
\text { se aprende }\end{array}$} & \multicolumn{3}{|c|}{$\begin{array}{l}\text { cómo } \\
\text { se aprende }\end{array}$} & \multicolumn{3}{|c|}{$\begin{array}{l}\text { cómo } \\
\text { se evalúa }\end{array}$} \\
\hline & $\begin{array}{l}\text { Ítem } \\
1\end{array}$ & $\begin{array}{l}\text { Ítem } \\
2\end{array}$ & $\begin{array}{l}\text { Ítem } \\
3\end{array}$ & $\begin{array}{l}\text { Ítem } \\
4\end{array}$ & $\begin{array}{l}\text { Ítem } \\
5\end{array}$ & $\begin{array}{l}\text { Ítem } \\
6\end{array}$ & $\begin{array}{l}\text { Ítem } \\
7\end{array}$ & $\begin{array}{l}\text { Ítem } \\
8\end{array}$ & $\begin{array}{l}\text { Ítem } \\
9\end{array}$ & $\begin{array}{l}\text { Ítem } \\
10\end{array}$ \\
\hline Teoría Directa & 1 & 3 & 2 & 2 & 1 & 1 & 8 & 1 & 1 & 3 \\
\hline Teoría Implícita & 4 & 3 & 6 & 12 & 6 & 17 & 4 & 6 & 14 & 8 \\
\hline Teoría Constructiva & 14 & 13 & 11 & 5 & 12 & 1 & 6 & 12 & 4 & 8 \\
\hline Total & 19 & 19 & 19 & 19 & 19 & 19 & 18 & 19 & 19 & 19 \\
\hline
\end{tabular}

Fuente: Elaboración propia.

En la tabla 7 podemos apreciar que, el modelo teórico que carga con la menor cantidad de respuestas es la Teoría Directa, seguido por la Teoría Implícita y la Teoría Constructiva.

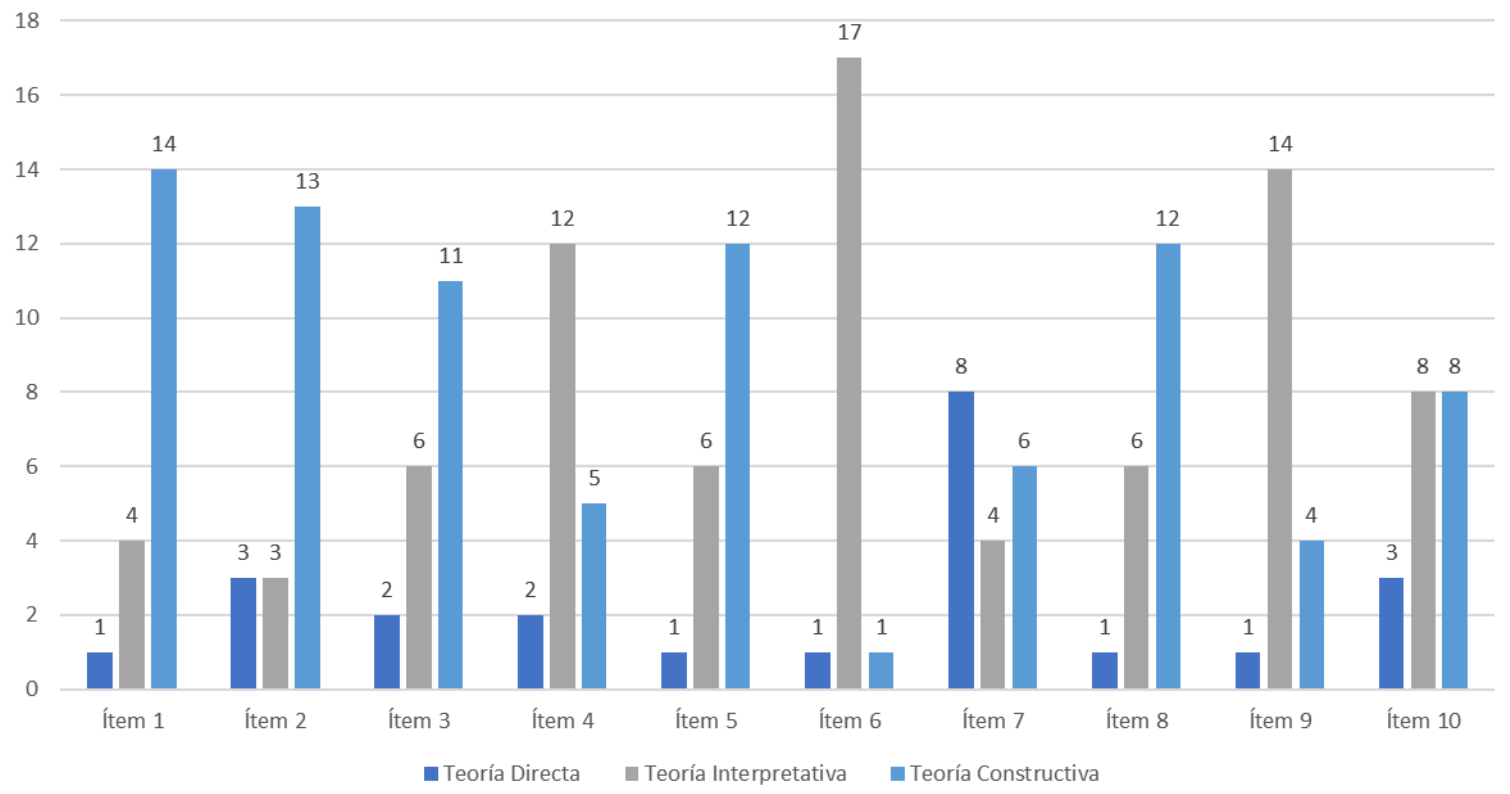


Figura 1 . Frecuencias según cada teoría analizada

En la figura 8 podemos apreciar cómo el ítem 6 carga con la más alta cantidad de respuesta relacionadas con la Teoría Interpretativa. Para la Teoría Constructiva, el ítem que más carga es el primero. Para la Teoría Directa, el ítem que mejor la representa es el $\mathrm{N}^{\mathrm{o}}$ 7. Este tipo de gráfico no permite hacer una lectura rápida desde qué modelo teórico se posicionan los participantes para responder las preguntas del cuestionario.

En la figura $\mathrm{N}^{\circ} 9$ podemos observar cómo se distribuye la carga en el factor "qué es aprender" en relación a cada modelo teórico teniendo en cuenta los valores máximos y mínimos expresados en el eje y.

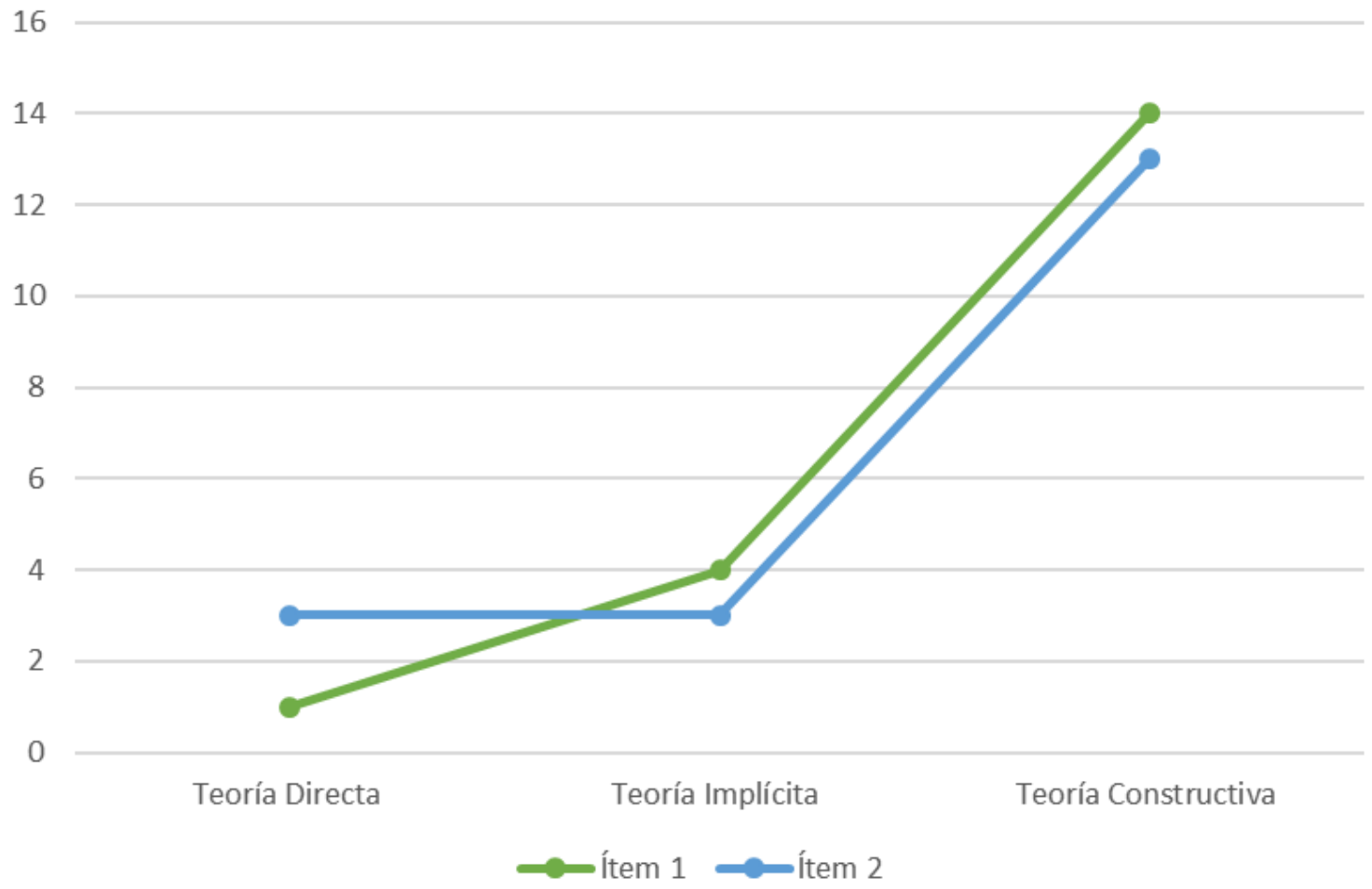

Figura 2. Distribución de Frecuencias según el factor "qué es aprender"

Podemos apreciar que la distribución de la carga en el factor "qué es aprender" tiende a concentrarse en la Teoría Constructiva.

En la figura 10 podemos observar cómo se distribuye la carga en el factor "qué se aprende" en relación a cada modelo teórico teniendo en cuenta los valores máximos y mínimos expresados en el eje y. Podemos apreciar que la distribución de la carga en el factor "qué se aprende" tiende a concentrarse en la Teoría Implícita, seguido por la Teoría Constructiva. 
14

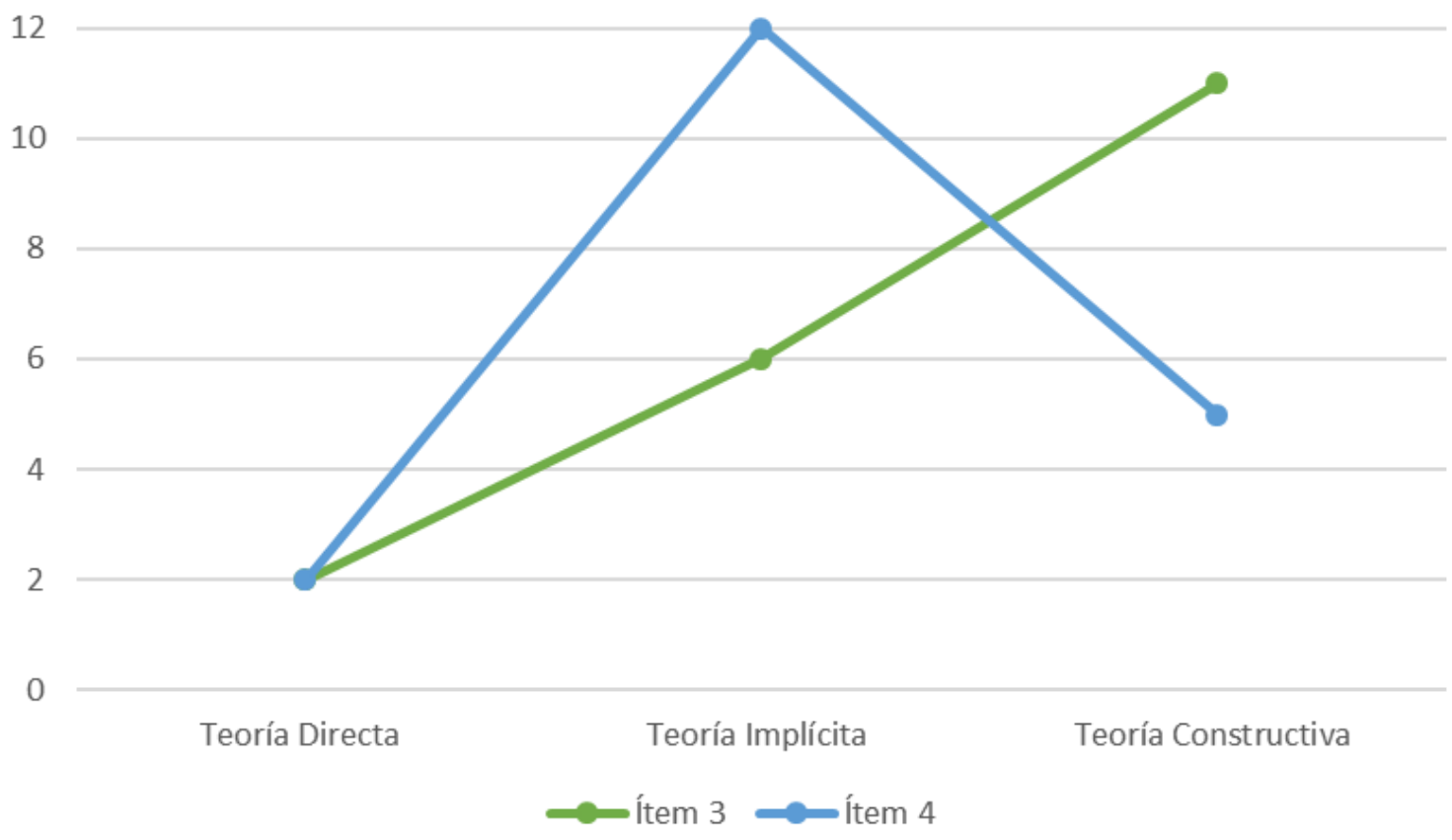

Figura 10. Distribución de Frecuencias según el factor "qué se aprende"

En la figura 11 podemos observar cómo se distribuye la carga en el factor "Cómo se aprende" en relación a cada modelo teórico teniendo en cuenta los valores máximos y mínimos expresados en el eje y.

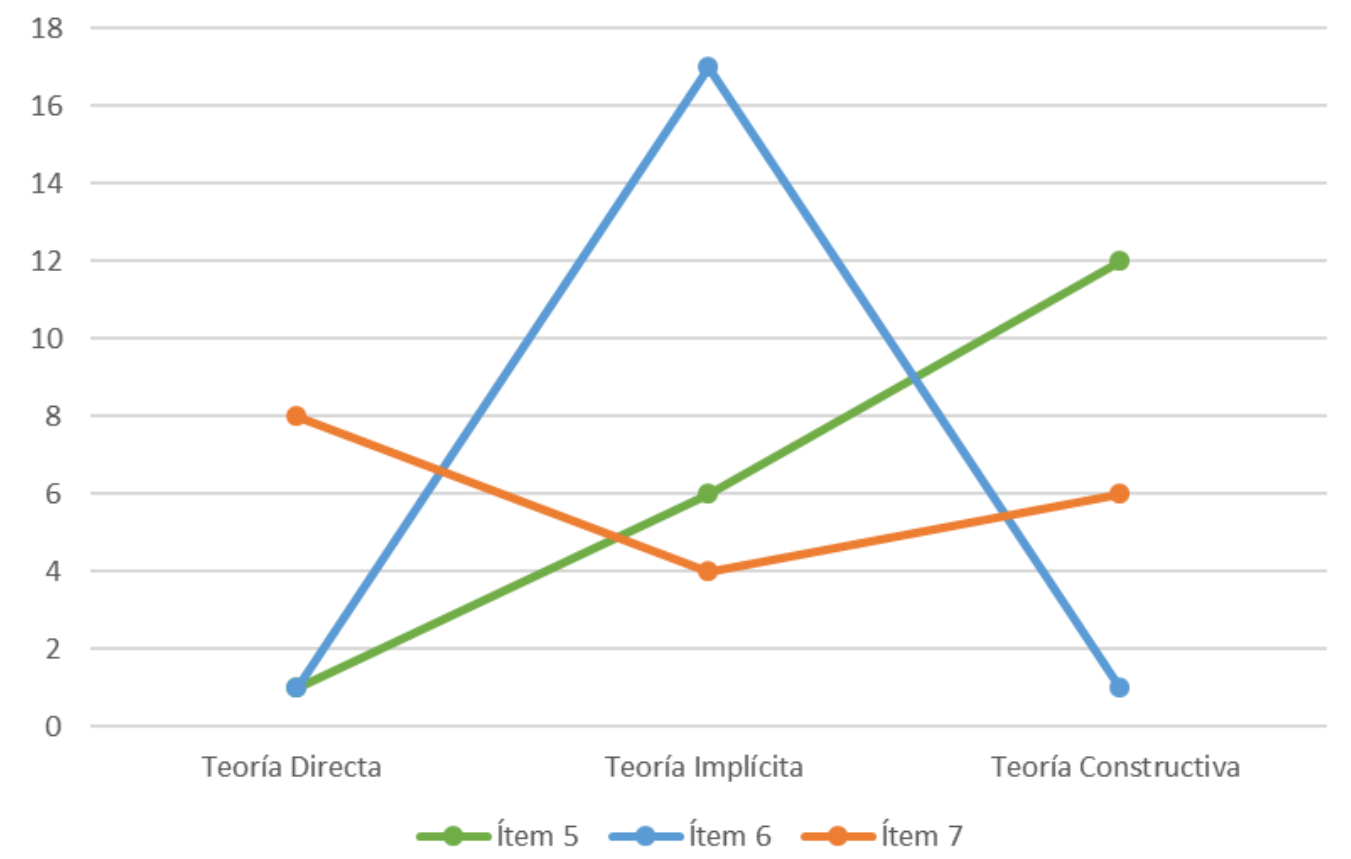

Figura 3. Distribución de Frecuencias según el factor “cómo se aprende"

Podemos apreciar que la distribución de la carga en el factor "cómo se aprende" tiende a dispersarse según el ítem analizado. Para el ítem 5 la carga es en la Teoría 
Constructiva; para el ítem 6, en la Teoría Implícita y para el ítem 7 en la Teoría Directa, respectivamente.

En la figura 12 podemos observar cómo se distribuye la carga en el factor "Cómo se evalúa" en relación a cada modelo teórico teniendo en cuenta los valores máximos y mínimos expresados en el eje y.

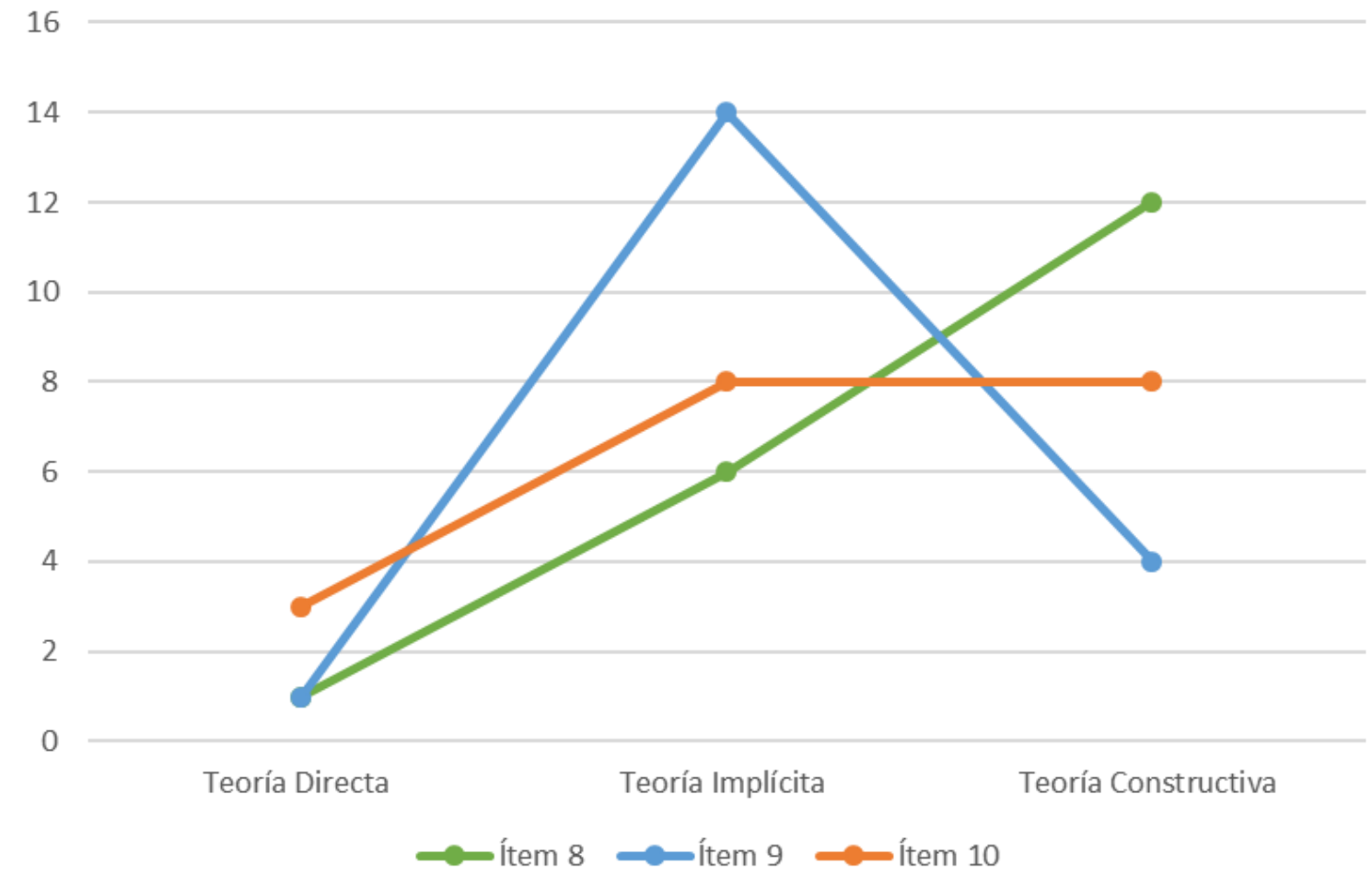

Figura 4: Distribución de Frecuencias según el factor "cómo se evalúa"

Podemos apreciar que la distribución de la carga en el factor "cómo se evalúa" también tiende a dispersarse según el ítem analizado, en dos de las teorías. Para el ítem 8 la carga es en la Teoría Constructiva; para el ítem 9, en la Teoría Implícita y para el ítem 10 en las Teorías Constructiva e Implícita.

En base a estos análisis podemos decir qué:

1.1.Existe una marcada predominancia de conceptuaciones basadas en las teorías Constructiva e Implícita, entre ambas conforman el 88\% del total de las respuestas.

En consecuencia, la Teoría Directa sólo cuenta con un $12 \%$ del total de las respuestas.

Existe una predominancia muy acentuada 4,6 y 9 de la Teoría Implícita.

Existe una predominancia muy acentuada 1 y 2 de la Teoría Constructiva.

Respecto de los factores:

Para el factor "qué es aprender" la predominancia es de la teoría Constructiva.

Para el factor "qué se aprende" la predominancia es de la teoría Constructiva.

Para el factor "cómo se aprende" la predominancia es de la teoría Indirecta.

Para el factor "cómo se evalúa" la predominancia es de la teoría Indirecta.

Mediante el análisis de documentos podremos verificar cuáles son los estadísticos descriptivos que componen la muestra y a cada grupo de análisis (Control y Experimental). Los factores analizados son los siguientes: 
Tabla 8

Organización del Currículum

Organización de su Enseñanza

Planificación de la Evaluación para el Aprendizaje

Respecto a los Objetivos de su Enseñanza

Respecto al Proceso de Evaluación

Estadísticos descriptivos de todos los factores que conforman "Pautas" según grupo de análisis

\begin{tabular}{|c|c|c|c|c|c|c|c|c|}
\hline & \multicolumn{2}{|c|}{ Total } & \multicolumn{3}{|c|}{ Grupo Control } & \multicolumn{3}{|c|}{ Grupo Experimental } \\
\hline & $\mathrm{N}$ & Media $\mathrm{DE}^{*}$ & $\mathrm{~N}$ & Media & $\mathrm{DE}^{*}$ & $\mathrm{~N}$ & Media & $\mathrm{DE}^{*}$ \\
\hline Organización del Currículum & 28 & $5,73212,02522$ & 6 & 2,5000 &, 63246 & 22 & 6,6136 & 1,17445 \\
\hline Organización de su Enseñanza & 28 & $6,46941,24713$ & 6 & 5,0000 & 1,33707 & 722 & 6,8701 &, 88822 \\
\hline $\begin{array}{l}\text { Planificación de la Evaluación } \\
\text { para el Aprendizaje }\end{array}$ & 28 & $4,32141,91105$ & 6 & 3,8333 & 1,50555 & 522 & 4,4545 & 2,01724 \\
\hline $\begin{array}{l}\text { Respecto a los Objetivos de su } \\
\text { Enseñanza }\end{array}$ & 28 & $6,17861,70628$ & 6 & 4,0833 & 1,35708 & 822 & 6,7500 & 1,30703 \\
\hline $\begin{array}{l}\text { Respecto al Proceso de } \\
\text { Evaluación }\end{array}$ & 28 & $3,14291,12462$ & 6 & 2,2667 & ,41312 & 22 & 3,3818 & 1,14294 \\
\hline $\mathrm{N}$ válido (por lista) & 28 & & 6 & & & 22 & & \\
\hline
\end{tabular}

Desviación Estándar

Fuente: Elaboración propia.

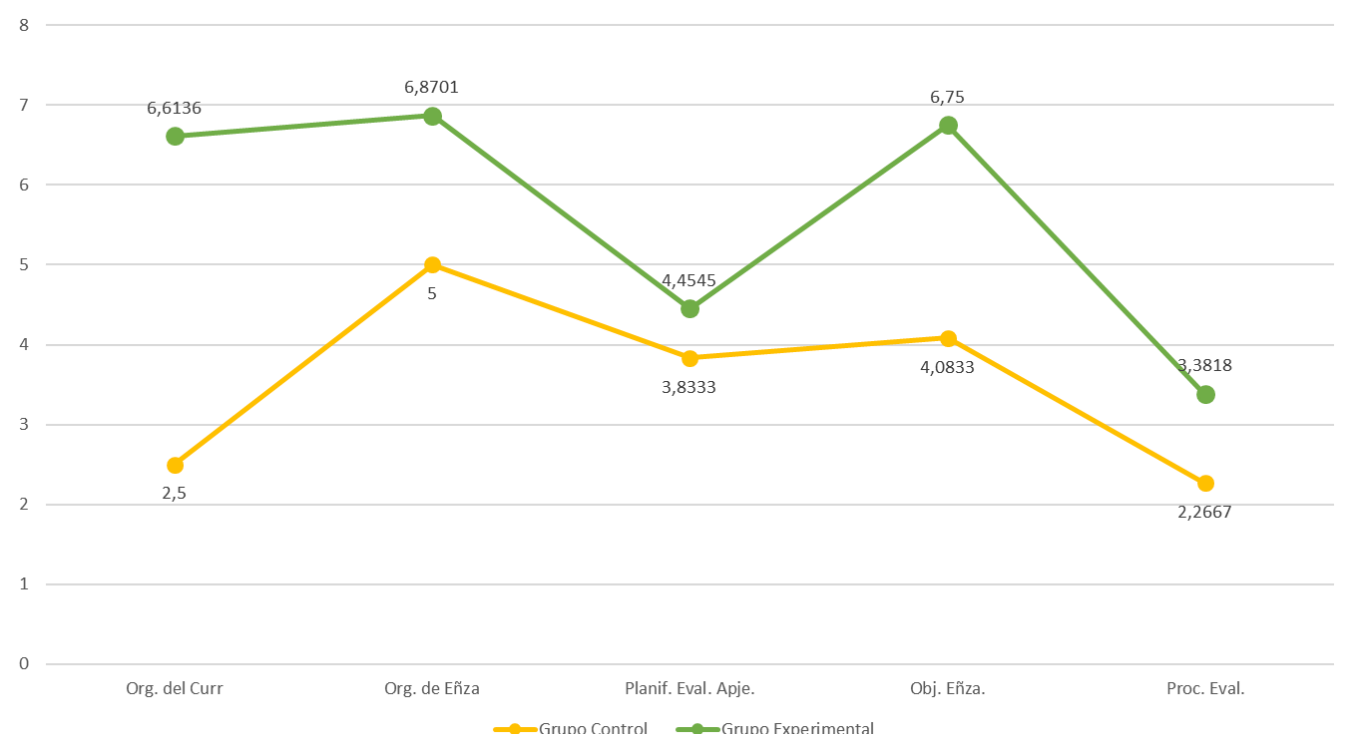

Figura 13. Medias de todos los factores que conforman "Pautas" según grupo de análisis.

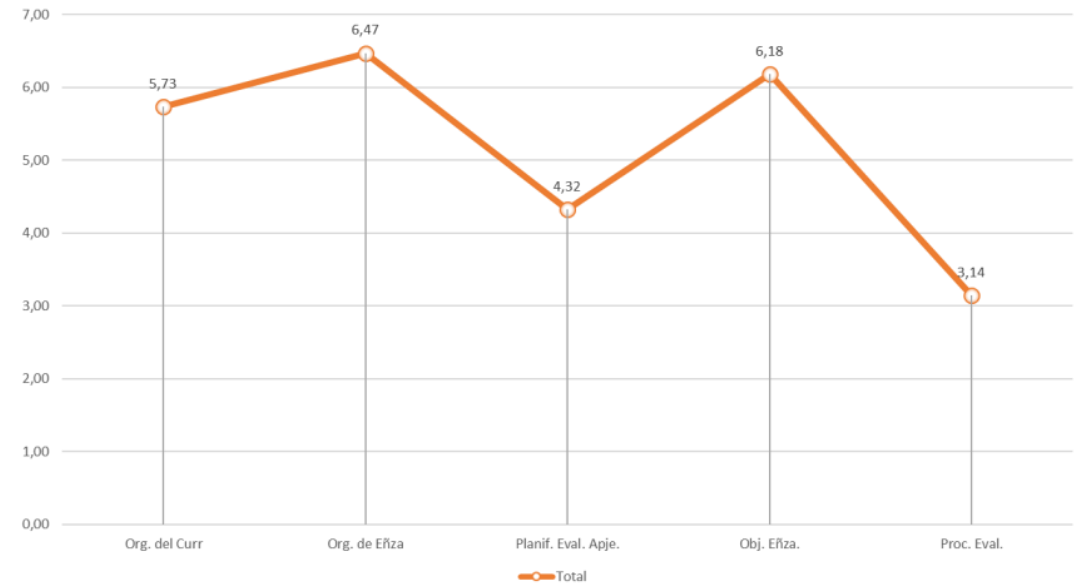


Figura 14. Medias de todos los factores que conforman "Pautas"

En estas figuras podemos observar las medias de los factores en escala 10 donde predominan los valores del grupo experimental sobre el control, sin embargo, las tendencias son similares.

\section{Discusión y conclusiones}

En el análisis de resultados obtenidos por medio del Diagnóstico Integral de estudio (DIE) encontramos una mejora sustantiva de todas las variables (Actitud y Estrategias de Apoyo, Autoconcepto y Estrategias complementarias, Actitud y Estrategias complementarias, Autoconcepto y Estrategias de Apoyo, Estrategias de Apoyo, Estrategias complementarias, Actitud, Autoconcepto y Aptitud) en los grupos de la Escuela Experimental (EE) en relación con los grupos de la Escuela Control (EC).

Entendemos que es un aporte valioso comprobar que hay un grado de incidencia del formato Taller sobre las estrategias de apoyo de los alumnos para que aprendan mejor. En las estrategias de apoyo se tomaron en cuenta: a) los factores externos como lugar, asignatura, tiempo; b) los factores internos como motivación, relajación y concentración y c) el prerrequisito de lectura para acercarnos a los logros en esa área del conocimiento. Pudimos comprobar que estar motivados conduce a los estudiantes a poner más esfuerzo en la tarea, provoca más iniciativas y mejora el involucramiento cognitivo afectando en forma directa los aprendizajes. Las variables medidas, tales como, actitud, autoconcepto y aptitud, estrategias de apoyo y estrategias complementarias, se acrecientan en el post test en la EE. En cambio, en la EC parece haber existido un estancamiento ya que ninguno de los factores logra superar la media ni en la primera ni en la segunda instancia de aplicación.

La mejora la adjudicamos a la implementación de la metodología Taller y se da respuesta a los dos primeros objetivos particulares: 1) ponderar la motivación para el aprendizaje de los alumnos a partir de la comparación entre las metodologías áulicas tradicional y taller y 2) evaluar los logros en el rendimiento de los niños a partir de la adquisición de procesos cognitivos básicos que se forman con la metodología taller.

También el Diagnóstico Integral de Estudio (DIE) nos aportó información sobre la actitud de los estudiantes frente al estudio. Se observó una correlación positiva entre el nuevo formato y las variables autoconcepto y actitud. En la segunda instancia de aplicación/post test, las medias en la EC quedaron significativamente por debajo de las medias en la EE. Esto indica que los factores involucrados en el aprendizaje, tales como actitud, aptitud y autoconcepto, mejoran al aplicar el nuevo formato pedagógico. Comprobamos que las prácticas de la escuela tradicional en la que se modifica el currículum para adaptarlo a las necesidades del alumnado, lo único que consiguen es reducir el nivel de los aprendizajes que deben alcanzarse durante la educación obligatoria, disminuir la intensidad de trabajo en áreas de contenidos más académicos a la vez que aumentar las tareas con finalidad ocupacional, de tipo manipulativo/manual o artístico.

El cuestionario de Dilemas (Vilanova et al, 2011) aplicado permitió visibilizar las teorías que dominan el accionar docente en la EE y subyacen a sus concepciones profesionales. Analizados los resultados, se puede afirmar que el formato Taller provoca cambios en las prácticas docentes. Existe una marcada predominancia de conceptuaciones basadas en las teorías Constructiva e interpretativa, entre ambas conforman el $88 \%$ del total de las respuestas. En consecuencia, la Teoría Directa sólo cuenta con un $12 \%$ del total de las respuestas. Es decir, más de las tres cuartas partes de los docentes entienden 
que la enseñanza debe apoyarse en metodologías activas, que los estudiantes deben participar vivamente en las tareas que se les propone y que el profesor juega un papel esencial en la creación de escenarios educativos significativos. En la documentación docente se pudo ver que los maestros implican a los estudiantes con metodologías activas que exigen participación e involucramiento. Los cuestionan, hacen que elaboren sus propias preguntas, que empleen su propio reservorio lingüístico para explicar situaciones.

Creemos que las exigencias sociales actuales hacia la educación exigen un modelo de intervención que facilite la escucha de las opiniones de los alumnos, de sus necesidades, de sus intereses y que conduzca al maestro a cambiar sus prácticas habituales de aula. La nueva metodología aparecerá en los centros, no por imposición externa, sino por convencimiento de los profesionales que allí se desempeñan, como una innovación sentida desde el centro mismo. El foco de la labor debe estar en el crecimiento institucional y profesional que conduzca al despegue académico de los estudiantes. La innovación será una herramienta que facilite la reflexión sobre la tarea realizada. La planificación diaria, a mediano y largo plazo surgirá por intercambio de experiencias y de forma colaborativa. Se generarán verdaderos cambios internos tanto para el centro como un todo, como para los estudiantes y para los maestros en su hacer profesional.

\section{Referencias}

Aponte Penso, R. (2015). El Taller como estrategia metodológica para estimular la imaginación en el proceso de enseñanza-aprendizaje en la educación superior. Boletín virtual octubre 4 (10), 49-55. Recuperado de https://dialnet.unirioja.es/descarga/articulo/6232367.pdf

Barber, M. y Mourshed, M. (2008). Cómo hicieron los sistemas educativos con mejor desempeño del mundo para alcanzar sus objetivos. Buenos Aires: PREAL

Bogliaccini, J. A. (2018). La educación en Uruguay mirada desde los Objetivos de Desarrollo Sostenible. Montevideo: INEEd y Unicef.

CEIP (2015). Monitor educativo. Recuperado de https://www.anep.edu.uy/monitor/servlet/portada

CEPAL (2017). Bases de datos y Publicaciones Estadísticas. Recuperado de http://estadisticas.cepal.org/cepalstat/web_cepalstat/estadisticasindicadores.asp

Fullan, M. y Langworthy, M. (2014). Una rica veta. Cómo las nuevas pedagogías logran el aprendizaje en profundidad. Londres: Pearson.

Martinis, P. y Stevenazzi, F. (2014). Movimientos y alteraciones de la forma escolar en la escuela primaria de Uruguay. Políticas Educativas, Porto Alegre, 7 (2), 89-109.

Pérez Avellaneda, M., Rodríguez Corps, E., Cabezas Fernández, M. y Polo Mingo, A. (2002). Diagnóstico integral del estudio, DIE, (niveles 1, 2 y 3). Madrid: TEA Ediciones.

Pozo, J.I., Scheuer, N., Pérez Echeverría, M.P., Mateos, M., Martín, E. y De la Cruz, M. (2006). Nuevas formas de pensar la enseñanza y el aprendizaje. Las concepciones de profesores y alumnos. Barcelona: Graó. 
Saavedra, A. y Opfer, V. (2012). Enseñanza y aprendizaje. Habilidades del siglo XXI: lecciones de las ciencias del aprendizaje. Un global Informe de la red de educación de las ciudades. Nueva York, Asia Society. Recuperado de http://asiasociety.org/files/rand-0512report.pdf

Stevenazzi, F. (2014). Una lectura sobre la producción de alteraciones a los formatos escolares desde la política cotidiana de la escuela. Revista científica Vozes dos $\begin{array}{lllll}\text { Vales } & 6 & \text { (3), } & 1-24 . & \text { Recuperado de }\end{array}$ http://site.ufvjm.edu.br/revistamultidisciplinar/files/2014/10/Una-lectura-sobrela-producci\%c3\%b3n-de-alteraciones-a-los-formatos-escolares-desde-lapol\%c3\%adtica-cotidiana-de-la-escuela.pdf

Vargas, A. (2018). Taller de coaching como instrumento para mostrar la apatía escolar como consecuencia de la falta de una dinámica adecuada. Tesis de Licenciatura. Perú: Universidad San Ignacio de Loyola.

Vermunt, J. D., y Verloop, N. (2000). Disonancia en regulación de los estudiantes de los procesos de aprendizaje. Revista Europea de Psicología de la Educación 15 (1), 75-89.

Vilanova, S., Mateos-Sanz, M.M. y García, M.B. (2011). Las concepciones sobre la enseñanza y el aprendizaje en docentes universitarios de ciencias. Revista Iberoamericana de Educación Superior Elsevier-España. Recuperado de

https://www.redalyc.org/pdf/2991/299124244003.pdf

Villar, L. (2013). Perfiles de aprendizaje y rendimiento académico en niñas de educación primaria. ¿Orientadas desde la autorregulación, la regulación externa o la carencia de regulación? Tesis de maestría. Venezuela: Universidad Católica Andrés Bello.

Fecha de recepción: 31/10/2019

Fecha de revisión: 18/03/2020

Fecha de aceptación: 27/03/2020 